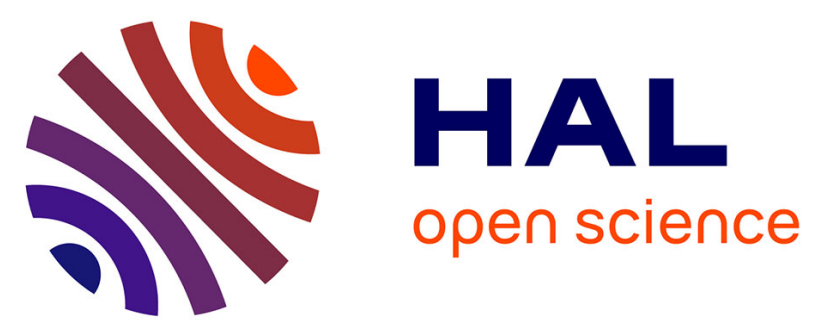

\title{
Gd- and Eu-loaded iron oxide@silica core-shell nanocomposites as trimodal contrast agents for magnetic resonance imaging and optical imaging
}

Sonia Pinho, José Sereno, Antero Abrunhosa, Marie-Hélène Delville, João Rocha, Luis D. Carlos, Carlos Geraldes

\section{To cite this version:}

Sonia Pinho, José Sereno, Antero Abrunhosa, Marie-Hélène Delville, João Rocha, et al.. Gdand Eu-loaded iron oxide@silica core-shell nanocomposites as trimodal contrast agents for magnetic resonance imaging and optical imaging. Inorganic Chemistry, 2019, 58 (24), pp.16618-16628. 10.1021/acs.inorgchem.9b02655 . hal-02416633

\section{HAL Id: hal-02416633 \\ https://hal.science/hal-02416633}

Submitted on 8 Sep 2020

HAL is a multi-disciplinary open access archive for the deposit and dissemination of scientific research documents, whether they are published or not. The documents may come from teaching and research institutions in France or abroad, or from public or private research centers.
L'archive ouverte pluridisciplinaire HAL, est destinée au dépôt et à la diffusion de documents scientifiques de niveau recherche, publiés ou non, émanant des établissements d'enseignement et de recherche français ou étrangers, des laboratoires publics ou privés. 


\section{Gd and Eu Loaded Iron Oxide@ Silica Core-Shell}

\section{Nanocomposites as Trimodal Contrast Agents for}

\section{MRI and Optical Imaging}

Sonia L. C. Pinho, ${ }^{*} a, b, c$ José Sereno, ${ }^{d}$ Antero J. Abrunhosa ${ }^{d}$ Marie-Hélène Delville, ${ }^{e}$ João

${\text { Rocha },{ }^{b} \text { Luís D. Carlos, }{ }^{b} \text { and Carlos F.G.C. Geraldes }}^{*} d, f, g$

a Center for Neurosciences and Cell Biology, University of Coimbra, 3001-401 Coimbra, Portugal.*E-mail: slpinho@uc-biotech.pt

b Departments of Chemistry and Physics, CICECO-Aveiro Institute of Materials, University of Aveiro, 3810-193 Aveiro, Portugal

c CIVG- Vasco da Gama Research Center, Vasco da Gama University School, Av. José R. Sousa Fernandes 197 Lordemão, 3020-210, Coimbra, Portugal

d CIBIT/ICNAS Instituto de Ciências Nucleares Aplicadas à Saúde. Pólo das Ciências da Saúde, Azinhaga de Santa Comba, 3000-548 Coimbra, Portugal

e CNRS, Univ. Bordeaux, Bordeaux INP, ICMCB, UMR 5026, 87 avenue du Dr. A. 
Schweitzer, Pessac, F-33608, France

f Department of Life Sciences, Faculty of Science and Technology, University of

Coimbra, Calçada Martim de Freitas, 3000-393 Coimbra, Portugal *E-mail: geraldes@uc.pt

g Chemistry Center, Rua Larga, University of Coimbra, 3004-535 Coimbra,

Portugal

\section{KEYWORDS}

Core-shell nanoparticles; Multimodal imaging agents; MRI contrast agents; $\mathrm{T}_{1}-\mathrm{T}_{2}$ contrast; $\mathrm{Eu}(\mathrm{III})$

luminescence 


\section{ABSTRACT}

Superparamagnetic maghemite core-porous silica shell nanoparticles, $\gamma-\mathrm{Fe}_{2} \mathrm{O}_{3} @ \mathrm{SiO}_{2}$ (FS), with $50 \mathrm{~nm}$ diameter and a $10 \mathrm{~nm}$ core, impregnated with paramagnetic complexes b-Ln $\left(\left[\operatorname{Ln}(\mathrm{btfa})_{3}\left(\mathrm{H}_{2} \mathrm{O}\right)_{2}\right]\right)($ where btfa $=4,4,4$-trifluoro-1-phenyl-1,3-butanedione and $\mathrm{Ln}=\mathrm{Gd}$, Eu, and $\mathrm{Gd} / \mathrm{Eu}$ ), performing as promising trimodal $T_{1}-T_{2} \mathrm{MRI}$ and optical imaging contrast agents, are reported. These nanosystems exhibit a high dispersion stability in water and no observable cytotoxic effects, witnessed by intracellular ATP levels. The structure and superparamagnetic properties of the maghemite core nanocrystals are preserved upon imbedding the b-Ln complexes in the shell. Hela cells efficiently and swiftly internalize the NPs into the cytosol, with no observable cytotoxicity below $62.5 \mu \mathrm{g} \mathrm{mL} \mathrm{L}^{-1}$ concentration. These nanosystems perform better than the free b-Gd complex as $T_{l}$ (positive) contrast agents in cellular pellets, while their performance as $T_{2}$ (negative) contrast agents is similar to the FS. Embedding of the b-Eu complex in the silica pores endows the nanoparticles with strong luminescence properties. The impregnation of gadolinium and europium complexes in a 1:1 ratio afforded a trimodal nanoplatform performing as a luminescent probe and a double $T_{1}$ and $T_{2}$ MRI contrast agent even more efficient than b-Gd used on its own, as observed in cell labeled imaging experiments and MRI cell pellets. 


\section{INTRODUCTION}

Magnetic resonance imaging (MRI) is among the most powerful clinical imaging modalities because it is non-invasive and ionizing radiation-free, providing tomographic images with large penetration depth, outstanding spatial resolution and high soft tissue contrast, resulting mostly from intrinsic differences in the spin-lattice $\left(T_{1}\right)$ and spin-spin relaxation times $\left(T_{2}\right)$ of tissue water protons. ${ }^{1}$ MRI contrast agents are often employed to enhance the contrast between normal and disease tissues by significantly decreasing $T_{1}$ and $T_{2}$ values. ${ }^{2-3} T_{1}$ contrast agents comprising paramagnetic materials, such as $\mathrm{Gd}^{3+}$ or $\mathrm{Mn}^{2+}$ chelates, prompt the spin-lattice relaxation of protons causing a positive (bright) MRI image contrast. ${ }^{4-5} T_{2}$ contrast agents commonly consisting of superparamagnetic materials, such as iron-oxide nanoparticles (NPs), induce protons in their vicinity to undergo spin-spin relaxation, originating negative (dark) MRI image contrast. ${ }^{6-7}$ Their efficacy is measured by the relaxivity, $r_{1}$ or $r_{2}$, defined as the paramagnetic enhancement of the water proton relaxation rates, normalized to $1 \mathrm{~m}_{\mathrm{M}}$ metal ion concentration..$^{2-3}$ While conventional MRI contrast agents respond only in a single imaging mode, NPs with multimodal capabilities provide complementary diagnostic information. However, when hybrid imaging systems are not available, different imaging devices must be deployed. ${ }^{8-11}$

Here, we propose a nanosystem comprising a core-shell system ${ }^{12}$ in which the superparamagnetic maghemite $\left(\gamma-\mathrm{Fe}_{2} \mathrm{O}_{3}\right)$ core is surrounded by a Stöber-type silica bearing micropores ${ }^{13}$ impregnated with a given amount of a paramagnetic complex $\left[\mathrm{Ln}(\mathrm{btfa})_{3}\left(\mathrm{H}_{2} \mathrm{O}\right)_{2}\right]$, here after referred to as b-Ln (with btfa $=(4,4,4$-trifluoro-1-phenyl-1,3-butanedione (Scheme S1)). The ensuing nanosystems, $\gamma$ $\mathrm{Fe}_{2} \mathrm{O}_{3} @ \mathrm{SiO}_{2} /\left[\mathrm{Gd}(\mathrm{btfa})_{3}\left(\mathrm{H}_{2} \mathrm{O}\right)_{2}\right]$, are dubbed FSb-Ln, $\mathrm{F}$ for ferrofluid and $\mathrm{S}$ for silica, $\mathrm{Ln}=\mathrm{Gd}, \mathrm{Eu}$ or $\mathrm{Gd} / \mathrm{Eu}$. In the case of $\mathrm{Gd}-$ bearing systems, while the $\mathrm{Gd}^{3+}$ complexes in direct contact with the surrounding water molecules increase $T_{l}$ relaxation, the long-range magnetic field of the core 
promotes $T_{2}$ relaxation. The microporous shell allows the modulation of the magnetic coupling between the two materials, prompting the simultaneous generation of strong $T_{1}$ and $T_{2}$ contrast effects. The isostructural b-Eu complex was also embedded together with the $\mathrm{Gd}^{3+}$ complex in the silica shell pores in a 1:1 molar ratio, endowing the nanosystem with emission properties and $T_{1^{-}}$ $T_{2}$ relaxivity.

\section{EXPERIMENTAL SECTION}

\section{Materials}

The chemicals $\mathrm{EuCl}_{3} \cdot 6 \mathrm{H}_{2} \mathrm{O}$ and $\mathrm{GdCl}_{3} \cdot 6 \mathrm{H}_{2} \mathrm{O}$ (Aldrich), 4,4,4-trifluoro-1-phenyl-1,3-butanedione (btfa, Aldrich), methanol (MeOH, Merck), sodium hydroxide (NaOH, Merck), iron (III) chloride hexahydrate (98\%) (Aldrich), iron (II) chloride tetrahydrate (99\%) (Aldrich), iron (III) nitrate nonahydrate (99\%) (Aldrich), tetraethoxysilane (TEOS) (98\%) (Aldrich), and citric acid (99.5\%)

(Aldrich); Nitric acid (Aldrich) were used as received. Absolute ethanol (J.T. Baker) and ammonia (28\%) (Carlo Erba) were used as received. Celltiter-Glo Luminescent Cell Viability Assay (Promega). All the experiments were performed in deionized Milli-Q water.

\section{Preparation of the maghemite ferrofluid suspension}

The aqueous maghemite suspension was synthesized according to published data. ${ }^{12}$ Briefly, $\mathrm{Fe}_{3} \mathrm{O}_{4}$ precipitates (black dispersion of magnetite), obtained by alkalinisation of the $\mathrm{FeCl}_{2}$ and $\mathrm{FeCl}_{3}$ $\left(\mathrm{Fe}^{2+} / \mathrm{Fe}^{3+}=1 / 2\right)$ aqueous mixture, were successively oxidized with $2 \mathrm{M} \mathrm{HNO}_{3}$ and $0.33 \mathrm{M}$ $\mathrm{Fe}\left(\mathrm{NO}_{3}\right)_{3} .9 \mathrm{H}_{2} \mathrm{O}$ solutions at $373 \mathrm{~K}$ in order to obtain particles with a $\mathrm{Fe}^{2+} / \mathrm{Fe}^{3+}$ ratio lower than 0.05. In the process, magnetite was converted into maghemite. The brown dispersion was peptized in a $2 \mathrm{M} \mathrm{HNO}_{3}$ solution under vigorous stirring in order to create positive surface charges. The 
acidic precipitate was isolated by magnetic separation, washed with acetone and dispersed at $\mathrm{pH}$ $\sim 2.5$ in water with nitric acid. The iron concentration was determined by volumetric titration and ICP and the average particle size, ascertained by transmission electron microscopy (TEM), was 10 $\pm 1 \mathrm{~nm},($ Figure S1-A, C)

\section{Preparation of the maghemite ferrofluid core-shell suspension}

The method was derived from the so-called Stöber process ${ }^{14}$ widely used for the synthesis of silica beads with diameters from a few tens to a few hundreds of nanometers. It is based on the hydrolysis/condensation of tetraethoxysilane (TEOS) catalyzed by ammonia in alcoholic media (ethanol). The surface of $\gamma-\mathrm{Fe}_{2} \mathrm{O}_{3}$ NPs was activated by acidic ( $0.01 \mathrm{M}$ citric acid) treatment of colloidal suspensions. NPs were isolated by decantation on a magnet. The particles were dispersed in water $(12 \mathrm{~mL})$ and peptization was performed by adding ammonia $(20 \mu \mathrm{L})$. Then, the alkaline solution of citrated- $\gamma-\mathrm{Fe}_{2} \mathrm{O}_{3}$ NPs was poured into ethanol-water-ammonia solution 75/23.5/1.5 $\mathrm{v} / \mathrm{v} / \mathrm{v} \%$ (1 L). Appropriate amounts of TEOS precursors were added to the dispersion under mild stirring to reach the targeted shell thickness. ${ }^{12}$ Under these conditions, no secondary nucleation was observed, in agreement with the results reported by Chen et al. ${ }^{15}$

\section{Preparation of $b$-Eu and $b-G d$, complex 1 and complex 2}

The synthesis followed a reported method, ${ }^{16}$ where $0.1 \mathrm{mmol}$ of $\mathrm{LnCl}_{3} \cdot 6 \mathrm{H}_{2} \mathrm{O}(\mathrm{Ln}=\mathrm{Eu}$ and $\mathrm{Gd})$ and $0.3 \mathrm{mmol}$ of Hbtfa were dissolved in ethanol $(1 \mathrm{~mL})$. The $\mathrm{pH}$ of the solution was adjusted to 6.5 with a $\mathrm{NaOH}$ ethanolic solution. The resulting mixture was stirred for $24 \mathrm{~h}$ at room temperature. The solvent was slowly evaporated at room temperature for $48 \mathrm{~h}$. The compound formed was washed with water and recrystallized in ethanol. 


\section{Preparation of the complex-grafted core-shell nanoparticles}

The core-shell NPs suspension $c a .50 \pm 6 \mathrm{~nm}$ (Figure S1-B, D) $\left(1.5 \mathrm{ml},\left[\mathrm{Fe}^{3+}\right]=0.0216 \mathrm{M}\right)$ was centrifuged and the supernatant discarded, the wet NPs were slowly re-suspended in $1 \mathrm{~mL}$ of an ethanol-complex solution containing b-Eu ((2.4 mg, $2.9 \mu \mathrm{mol}), \mathrm{b}-\mathrm{Gd}(2.4 \mathrm{mg}, 2.9 \mu \mathrm{mol})$ or b-Eu $(1.2 \mathrm{mg}, 1.45 \mu \mathrm{mol})$ and $\mathrm{b}-\mathrm{Gd}(1.2 \mathrm{mg}, 1.45 \mu \mathrm{mol})$ at room temperature. The system was sonicated for 15 min. and dried in an oven at $333 \mathrm{~K}$ for $12 \mathrm{~h}$. The FSb-Ln Ln ( $\mathrm{Ln}=\mathrm{Gd}, \mathrm{Eu}$, or Gd/Eu) particles were then re-suspended and filtered in $\mathrm{dd}_{2} \mathrm{O}(5 \mathrm{~mL})$.

\section{Leaching analysis}

In order to assess the possible leaching of $\mathrm{Gd}^{3+}$ from the NPs, the detection of free $\mathrm{Gd}^{3+}$ ions was determined by the procedures described in refs. ${ }^{17-18}$ Briefly, xylenol orange $(3.42 \mathrm{~g}, 4.7 \mathrm{mmol})$ was dissolved in buffer solution $(250 \mathrm{~mL}$, acetic acid and $\mathrm{NaOH}, \mathrm{pH}=5.8)$ and the solution was then stored at $277 \mathrm{~K}$ for one week. Furthermore, an aqueous dispersion of FSb-Gd NPs ( $2 \mathrm{~m}_{\mathrm{M}}, 5.18$ $\mathrm{mg} / \mathrm{mL}$ ) in the buffer solution was also stored at $277 \mathrm{~K}$ for a week. A calibration curve was built with free $\mathrm{Gd}^{3+}$ ions in solutions $(0-70 \mu \mathrm{M})$, prepared with the buffer solution by dissolving $\mathrm{Gd}_{2} \mathrm{O}_{3}$ with nitric acid $\left(\mathrm{HNO}_{3}\right)$. The calibration curve was determined from the plot of the $\mathrm{Gd}^{3+}$ concentration $v s$. the ratio of the integrated intensities of the UV-visible absorption bands at 573 and 433 nm, measured on Synergy H1 Multi-Mode Reader - BioTek Instruments (Figure S2-A) Finally, the absorption spectrum of an aqueous dispersion of FSb-Gd in the buffer solution was recorded under the same experimental conditions as those used for the calibration curve data and the amount of free $\mathrm{Gd}^{3+}$ was estimated from the curve (Figure S2-B). 


\section{Physico-chemical characterization of the nanoparticles}

The morphology of the samples was analyzed by electron microscopy on a Hitachi STEM HD2700 electron microscope in the scanning (SEM) and transmission (TEM) modes operated at $200 \mathrm{kV}$, coupled with a Bruker Quantax Esprit 2.0 energy-dispersive X-ray spectroscopy (EDS) for elemental analysis and mapping. Drops of diluted dispersions of NPs were air-dried on carbon films deposited on 200-mesh copper grids. The excess liquid was blotted with filter paper.

Diffuse Reflectance Infrared Fourier-Transform (DRIFT) spectra were recorded on a Bruker IFS Equinox 55FTIR spectrometer (signal averaging 64 scans at a resolution of $4 \mathrm{~cm}^{-1}$ in $\mathrm{KBr}$ pellets containing $c a .2$ mass $\%$ of material). The zeta potential of the NPs was measured using a Zetasizer 3000HSA setup (Malvern Instruments) equipped with a He- Ne laser (50 mW, $532 \mathrm{~nm}$ ). The zeta potential measurement based on laser Doppler interferometry was used to measure the electrophoretic mobility of NPs. Measurements were performed for $20 \mathrm{~s}$ using a standard capillary electrophoresis cell. The dielectric constant was set to 80.4 and the Smoluchowsky constant f(ka) was 1.5. The silica, iron, europium, and gadolinium contents were measured by inductively coupled plasma / optical emission spectrometry ICP/MS (ES720, Varian) equipped with a crossflow nebulizer. Solutions for each element with a concentration of $1 \mathrm{~g} / \mathrm{L}$ were used to prepare the standard solutions (SCP Science to Paris) and were used as internal standard to evaluate the instrumental drift.

The photoluminescence spectra were recorded at room temperature with a modular double grating excitation spectrofluorimeter with a TRIAX 320 emission monochromator (Fluorolog-3, Jobin Yvon-Spex) coupled to a R928 Hamamatsu photomultiplier, using the front face acquisition mode. The excitation source was a $450 \mathrm{~W}$ Xe arc lamp. The emission spectra were corrected for detection and optical spectral response of the spectrofluorimeter and the excitation spectra were weighed for 
the spectral distribution of the lamp intensity using a photodiode reference detector. Lifetimes were measured with the setup described for the luminescence spectra using a pulsed Xe-Hg lamp (6 $\mu$ s pulse at half width and 20-30 $\mu$ s tail). The absolute emission quantum yields were measured at room temperature using a Quantum Yield Measurement System C9920-02 from Hamamatsu with a $150 \mathrm{~W}$ Xenon lamp coupled to a monochromator for wavelength discrimination, an integrating sphere as sample chamber and a multi-channel analyzer for signal detection.

The magnetic properties of the nanoparticles were measured on a known amount of the ferrofluids using a vibrating sample magnetometer VSM-NUVO (MOLSPIN, Newcastle Upon Tyne, U.K.). The magnetization was studied as a function of applied magnetic field $[M(H)]$ at a temperature of 298K.

\section{Relaxivity and MRI phantom studies}

${ }^{1} \mathrm{H}$ longitudinal and transverse relaxation times $\left(\mathrm{T}_{1}\right.$ and $\mathrm{T}_{2}$, respectively) of aqueous suspensions of NPs were measured at 9.4T (400 MHz) using a BRUKER 94/20 USR small animal scanner, from $\mathrm{T}_{1}$ Map-RARE images of phantoms using a spin-echo sequence $(\mathrm{TE}=12 \mathrm{~ms}, \mathrm{TR}=50 ; 250$; $450 ; 650 ; 850 ; 1050 ; 1250 ; 1450 ; 1650 ; 1850 \mathrm{~ms}, \mathrm{FOV}=33 \times 22 \mathrm{~mm}$, slice thickness $=2.00 \mathrm{~mm}$, matrix $=264 \times 176$, resolution $=125 \times 125 \mathrm{~mm}, 2$ averages, time acquisition of $27 \mathrm{~min}$ and $52 \mathrm{sec}$ ) and a $\mathrm{T}_{2}$-Map from a 2D Multi-Slice-Multi-Echo (MSME) sequence $(\mathrm{TR}=4000 \mathrm{~ms}, \mathrm{TE}=20 ; 40$; $60 ; 80 ; 100 ; 120 ; 140 ; 160 ; 180 ; 200 \mathrm{~ms}, \mathrm{FOV}=33 \times 22 \mathrm{~mm}$, matrix $=264 \times 176$, resolution $=$ $125 \times 125 \mathrm{~mm}, 2$ averages, time acquisition of $23 \mathrm{~min}$ and $28 \mathrm{sec}$ ). All the experimental values were corrected for the diamagnetic contributions of water under the same conditions. The relaxivity values $r_{1}$ and $r_{2}$ were calculated from the slopes of the linear plots of the experimental relaxation 
rates $1 / \mathrm{T}_{\mathrm{i}}(\mathrm{i}=1,2)$ against the total metal concentration $[\mathrm{M}]$ (where $\mathrm{M}=\mathrm{Gd}, \mathrm{Fe}, \mathrm{Fe}+\mathrm{Gd}$ or $\mathrm{Fe}+$ $\mathrm{Gd}+\mathrm{Eu}$, in $\mathrm{mM})$, in accordance with:

$$
1 / \mathrm{T}_{\mathrm{i}}=1 / \mathrm{T}_{\mathrm{i}, 0}+\mathrm{r}_{\mathrm{i}}[\mathrm{M}] \quad(\mathrm{i}=1,2)
$$

where $T_{i, 0}$ is the relaxation time of pure water in the absence of the contrast agent (diamagnetic contribution).

\section{Cell cultures and in vitro cell imaging}

Hela cells were grown in Dulbecco's modified Eagle's medium (DMEM) supplemented with $10 \%$ (v/v) fetal bovine serum (FBS), $10 \mathrm{U} / \mathrm{mL}$ penicillin, and $10 \mu \mathrm{g} \cdot \mathrm{mL}^{-1}$ streptomycin at $310 \mathrm{~K}$ in fully humidified air containing $5 \% \mathrm{CO}_{2}$. The cells were fed every $2-3 \mathrm{~d}$. The cells were passaged after reaching $80 \%$ confluency. Hela cells $\left(5 \times 10^{5}\right.$ cells/well $)$ were plated in six-well plates and left to adhere overnight. Then, the cells were incubated with NPs $(50 \mu \mathrm{g} / \mathrm{mL})$ for 1,2 and $6 \mathrm{~h}$. After incubation, to remove non-internalized NPs, the cells were washed three times with phosphatebuffered saline (PBS), dissociated with trypsin $[0.2 \%(\mathrm{w} / \mathrm{v})$ in PBS], centrifuged and counted. Afterwards, the samples were freeze-dried, and the presence of $\mathrm{Fe}, \mathrm{Si}, \mathrm{Gd}$ and $\mathrm{Eu}$ in the samples was evaluated by ICP-MS (ES720, Varian) equipped with a crossflow nebulizer. For this purpose, the samples were digested overnight in the presence of nitric acid $(0.5 \mathrm{~mL}, 68 \% \mathrm{w} / \mathrm{v})$, and hydrofluoric acid $(0.5 \mathrm{~mL}, 48 \% \mathrm{w} / \mathrm{v})$. Dilution of the sample was performed by addition of $\mathrm{ddH}_{2} \mathrm{O}$ $(1 \mathrm{~mL})$. The samples $(\mathrm{n}=3)$ were analyzed by ICP-MS to quantify internalized Gd and Eu. ${ }^{19}$

Hela cells $\left(7 \times 10^{3}\right.$ cells/well) were seeded onto a 96-well plate and left to adhere. The cells were then incubated for $4 \mathrm{~h}$ with NPs with different concentrations $\left(15.625,31.25,62.5,125 \mu \mathrm{g} \cdot \mathrm{mL}^{-1}\right)$. After incubation, to remove non-internalized NPs, the cells were washed three times with phosphate-buffered saline (PBS). After 20h and 44h ATP production was measured by a Synergy 
H1 Multi-Mode Reader - BioTek Instruments using the Celltiter-Glo Luminescent Cell Viability Assay (Promega).

NPs tracking was assessed on Hela cells $\left(4 \times 10^{4}\right.$ cells/well), which were treated with $50 \mu \mathrm{g} / \mathrm{mL}$ FSb-Gd, FSb-Eu or FSb-EuGd NPs for 4 hours. After the incubation periods, cells were washed extensively with PBS and fixed with $4 \%$ paraformaldehyde, for $15 \mathrm{~min}$ at room temperature, and rinsed again with PBS. Cell membrane was stained with WGA (633, invitrogen), and the slides were mounted with mounting medium (Dako). Quantification was examined with a Zeiss LSM 710 confocal microscope analysed by classical quantification tools in ImageJ software. For MRI studies of labelled Hela cells, they were incubated with the NPs (FSb-Eu) at $310 \mathrm{~K}$, under $5 \% \mathrm{CO}_{2}$, for 4 hours. After this incubation, cells were washed with PBS, fixed with 4\% paraformaldehyde, for $15 \mathrm{~min}$ at room temperature, and rinsed again with PBS. Then, cells were detached from the culture flasks by scraping, the cell suspensions were prepared in PBS and the cell pellets were obtained by centrifugation at $180 \mathrm{~g}$ during $5 \mathrm{~min}$. $\mathrm{T}_{1}$-weighted MRI images of the cellular pellets were acquired at 9.4T (400 MHz) using a BRUKER 94/20 USR small animal scanner, from $\mathrm{T}_{1}$ Map-RARE images using a spin-echo sequence $(\mathrm{TE}=12 \mathrm{~ms}, \mathrm{TR}=50 ; 250 ; 450 ; 650 ; 850 ; 1050$; $1250 ; 1450 ; 1650 ; 1850 \mathrm{~ms}, \mathrm{FOV}=33 \times 22 \mathrm{~mm}$, slice thickness $=2.00 \mathrm{~mm}$, matrix $=264 \times 176$, resolution $=125 \times 125 \mathrm{~mm}, 2$ averages, time acquisition of $27 \mathrm{~min}$ and $52 \mathrm{sec}$ ) and a $\mathrm{T}_{2}$-Map from a 2D Multi-Slice-Multi-Echo (MSME) sequence $(\mathrm{TR}=4000 \mathrm{~ms}, \mathrm{TE}=20 ; 40 ; 60 ; 80 ; 100 ; 120$; $140 ; 160 ; 180 ; 200 \mathrm{~ms}, \mathrm{FOV}=33 \times 22 \mathrm{~mm}$, matrix $=264 \times 176$, resolution $=125 \times 125 \mathrm{~mm}, 2$ averages, time acquisition of $23 \mathrm{~min}$ and $28 \mathrm{sec}$ ). 


\section{RESULTS AND DISCUSSION}

\section{Synthesis and characterization of the nanoparticles}

Iron oxide NPs coated with silica $\left(\gamma-\mathrm{Fe}_{2} \mathrm{O}_{3} @ \mathrm{SiO}_{2}\right)$ were synthesized by coprecipitation and stabilized by the Stöber process. ${ }^{12,20}$ This procedure uses tetraethoxysilane (TEOS) as the silane monomer and alcohol-water-ammonia as the medium, providing a uniform silica coating with controllable thickness. ${ }^{12}$ Acid treatment improved the silica coating, activating the NPs surface, and leading to a simple and reproducible method for the production of monodispersed water stable quasi-spherical NPs, with a core average diameter of $10 \pm 2 \mathrm{~nm}$, and a ca. $20 \mathrm{~nm}$ thick silica shell (Figure 1A). The presence of the $\mathrm{Ln}^{3+}$ complex in the $\mathrm{SiO}_{2}$ shell was confirmed by energydispersive X-ray spectroscopy (EDS) elemental mapping. Figure 1B-E shows that silicon and the Ln ions are homogenously distributed throughout the shell. ICP-MS analysis was used to ascertain the $\mathrm{Fe} / \mathrm{Eu}$ and $\mathrm{Fe} / \mathrm{Gd}$ elemental ratios. As the same iron-silica core/shell was used for all the NPs, the amount of $\mathrm{Ln}^{3+}$ ions within the NPs can be compared based on the Fe/Ln ratios. As shown in Table 1, the ratios obtained are within the experimental error, leading to the conclusion that $\mathrm{b}-\mathrm{Eu}$ and $b-G d$ are present in the shell in a 1:1 molar ratio.

Table 1. Elemental ratios of NPs determined by ICP-MS.

\begin{tabular}{llll}
\hline Nanoparticles & Fe/Si ratio & Fe/Eu ratio & Fe/Gd ratio \\
\hline FS & $0.018 \pm 0.003$ & - & - \\
FSb-Eu & $0.018 \pm 0.003$ & $0.227 \pm 0.009$ & - \\
FSb-Gd & $0.018 \pm 0.003$ & - & $0.239 \pm 0.007$ \\
FSb-EuGd & $0.018 \pm 0.003$ & $0.137 \pm 0.005$ & $0.120 \pm 0.008$ \\
\hline
\end{tabular}

Diffuse reflectance infrared Fourier transform (DRIFT) was used to identify and characterize the bare iron oxide NPs, the effective coating of silica, and the embedded lanthanide complexes 
(Figures S3 A and B). The two characteristic peaks of bare iron oxide at 582 and $636 \mathrm{~cm}^{-1}$ are assigned to the $\mathrm{Fe}-\mathrm{O}$ bonds which are ascribed respectively to the stretching mode $\mathrm{Fe}-\mathrm{O}$ in octahedral site for the first one and the Fe-O stretching modes in octahedral and tetrahedral sites for the second one, while that around $440 \mathrm{~cm}^{-1}$ is related to symmetric stretching vibration modes of $\mathrm{Fe}-\mathrm{O}$ bonds on the octahedral sites. ${ }^{21}$ The bands at 3400 and $1600 \mathrm{~cm}^{-1}$ correspond to the $\mathrm{O}-\mathrm{H}$ stretching and bending vibrations of adsorbed water, respectively. The thin band at $1390 \mathrm{~cm}^{-1}$ is ascribed to the mode of elongation of the ions nitrate ions. ${ }^{22}$ Comparison of the DRIFT spectra of $\mathrm{SiO}_{2}$ and FS $\left(\gamma-\mathrm{Fe}_{2} \mathrm{O}_{3} @ \mathrm{SiO}_{2}\right)$ samples (Figure S3-A) lead to the assignment of all the new absorption bands of the latter to silica, witnessing the coating of the maghemite surface. ${ }^{23}$ The additional bands at $1866 \mathrm{~cm}^{-1}, 1105 \mathrm{~cm}^{-1}, 937 \mathrm{~cm}^{-1}$ and $802 \mathrm{~cm}^{-1}$ (arrows on Figure S3-A) are assigned to $\mathrm{Si}-\mathrm{O}$ and $\mathrm{Si}-\mathrm{O}-\mathrm{Si}$ asymmetric stretching modes ${ }^{24}$ The presence of the lanthanide complexes in the $\gamma-\mathrm{Fe}_{2} \mathrm{O}_{3} @ \mathrm{SiO}_{2} \mathrm{NPs}$ was confirmed by the characteristic btfa ligand $\mathrm{C}=\mathrm{O}$ band at $1613 \mathrm{~cm}^{-1}$, (Figure S3-B) and by the broadening of the 1000-1344 $\mathrm{cm}^{-1}$ band due to the overlap of the C-F stretching bands at $1182 \mathrm{~cm}^{-1}$. 


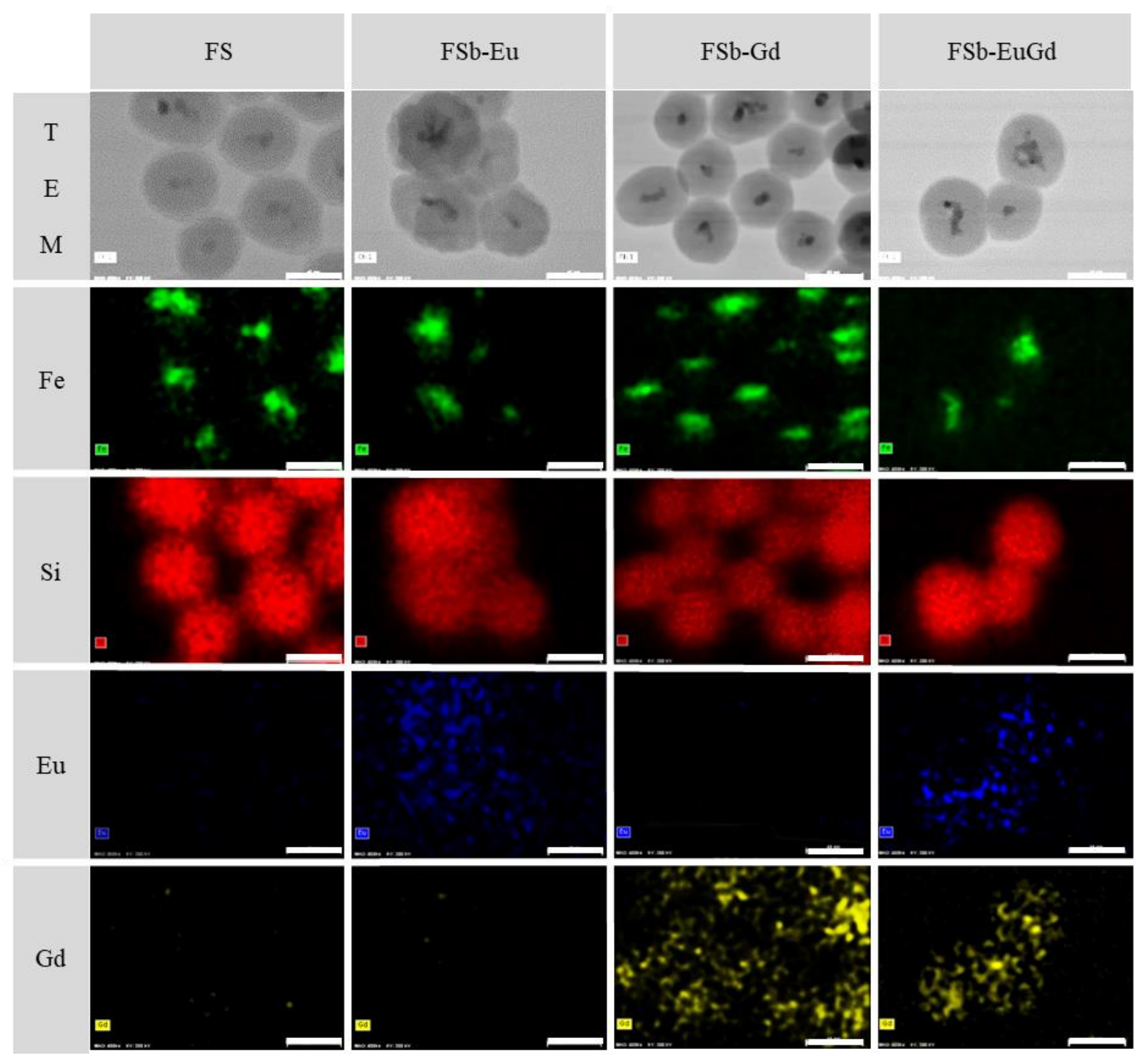

Figure 1: TEM images of FS, FSb-Eu, FSb-Gd and FSb-EuGd. Element mapping of Fe (green), Si (red), Eu (blue) and Gd (yellow) of the synthesized NPs. Scale bare is $40 \mathrm{~nm}$.

The properties of the NPs in aqueous suspensions were studied. Zeta potential titrations as a function of the $\mathrm{pH}$ (Figure S4) gave the $\mathrm{pH}$ range of stability and the isoelectric point: 7.0 for $\mathrm{F}$ NP, 2.3 for FS NP, 3.5 for FSb-Ln ( $\mathrm{Ln}: \mathrm{Gd}$, Eu and Eu/Gd). The shift of the isoelectric point towards lower $\mathrm{pH}$ values (from 7.0 to 2.3 ) upon silica coating provides an additional confirmation 
of a successful coating. ${ }^{25}$ Incorporation of b-Ln within the silica shell shifts the isoelectric points again towards higher $\mathrm{pH}$ (from 2.3 to 3.5), with a loss of surface anionic charge. Despite this loss, the very negative NPs zeta potential $(-40 \mathrm{mV})$ at physiological $\mathrm{pH}$ suggests the aqueous suspensions should remain stable in in vivo conditions, and do not flocculate at $\mathrm{pH}$ 7. Leaching of the free $\mathrm{Ln}^{3+}$ cation is a major toxicity issue hindering the use of $\mathrm{Gd}^{3+}$ complexes as MRI contrast agents. ${ }^{26}$ Therefore, the amount of free $\mathrm{Gd}^{3+}$ ions in FSb-Gd solutions was ascertained by the xylenol orange test. ${ }^{17}$ Only $0.39 \%$ of the metal ion leached into the solution (Figure S2). As the stability constants of $b-E u$ and $b-G d$ complexes are expected to be similar, the same leaching profile is expected for both complexes.

\section{Photoluminescence properties}

Luminescence studies of FSb-Eu and FSb-EuGd were performed in solution and in the solid state.

Figure 2 shows for example the $300 \mathrm{~K}$ emission and excitation spectra of FSb-Eu in the solid state, excited at two different wavelengths. Clearly, no energy shifts are observed for the transitions when the wavelength is varied, indicating the presence of a single $\mathrm{Eu}^{3+}$ local environment. This conclusion is also valid for suspensions of NPs, for which the only difference relative to the solidstate spectrum is the relative intensity of the intra-4f Stark components (Figure S5). The spectra consist of a series of lines ascribed to the ${ }^{5} \mathrm{D}_{0} \rightarrow{ }^{7} \mathrm{~F}_{0-4}$ transitions upon 270 and $310 \mathrm{~nm}$ excitation (assigned to host excited states), providing clear evidence of host-to-Eu ${ }^{3+}$ energy transfer. Comparison of the emission spectra of b-Eu and FSb-Eu in Figure 3 (in particular the energy and full-width-at-half-maximum of the ${ }^{5} \mathrm{D}_{0} \rightarrow{ }^{7} \mathrm{~F}_{1}$ lines, and the energy and relative intensities of the ${ }^{7} \mathrm{~F}_{2-4}$ Stark components), indicates an effective interaction between the $\mathrm{Eu}^{3+}$ ions and the $\mathrm{FSb}$ host, completely different from that observed for the b-Eu complex. 
To get further insight into the $\mathrm{Eu}^{3+}$ local coordination, high resolution spectra of the $4 \mathrm{f}^{6}$ emission lines were acquired (Figure 2 C-E). The detection of a single ${ }^{5} \mathrm{D}_{0} \rightarrow{ }^{7} \mathrm{~F}_{0}$ line $\left(17262 \pm 1 \mathrm{~cm}^{-1}\right)$ and the J-degeneracy splitting of the ${ }^{7} \mathrm{~F}_{1,2}$ levels into three Stark components, observed over the entire range of excitation wavelengths used, indicate the $\mathrm{Eu}^{3+}$ cations reside in a single low-symmetry site. The larger intensity of the electric-dipole ${ }^{5} \mathrm{D}_{0} \rightarrow{ }^{7} \mathrm{~F}_{2}$ transition relatively to the intensity of the magnetic-dipole ${ }^{5} \mathrm{D}_{0} \rightarrow{ }^{7} \mathrm{~F}_{1}$ transition indicates the absence of an inversion center for the $\mathrm{Eu}^{3+}$ site, since Laporte's rule is relaxed due to odd parity terms in the ligand field Hamiltonian.

The energy of the ${ }^{5} \mathrm{D}_{0} \rightarrow{ }^{7} \mathrm{~F}_{0}$ transition (Figure 3C) of b-Eu does not change following NPs incorporation, supporting the absence of covalent interactions between the metal complex and the NPs. The calculated value of the ${ }^{5} \mathrm{D}_{0} \rightarrow{ }^{7} \mathrm{~F}_{0}$ FWHM for the NPs is slightly larger $\left(c a .36 \mathrm{~cm}^{-1}\right)$ than the value for the b-Eu complex ( $\left.c a .26 \mathrm{~cm}^{-1}\right)$, suggesting a larger distribution of chemical environments for the $\mathrm{Eu}^{3+}$ ions. This can be explained by changes occurring outside the coordination polyhedron, essentially related to the physical interaction between the complex and the silica shell. The same phenomenon takes place for the FSb-Eu NP suspension (Figure S5), leading to the conclusion that no complex has escaped the NPs system. 

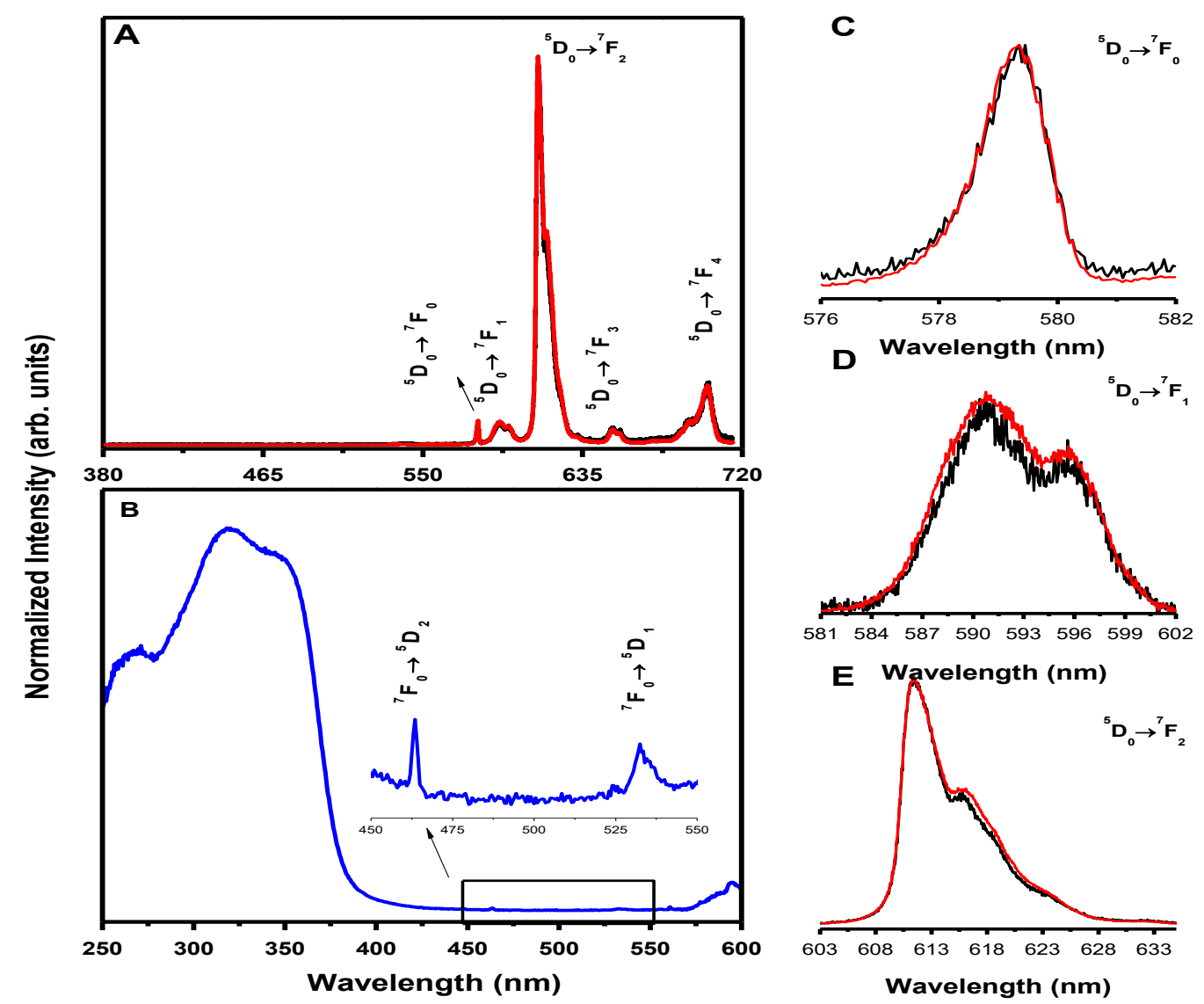

Figure 2: A) Emission spectra (300K) of FSb-Eu (solid state) excited at $270 \mathrm{~nm}$ (black) and 310 $\mathrm{nm}(\mathrm{red}) ; \mathrm{B}$ ) Excitation spectra (300K) of FSb-Eu (solid state) monitored at $612 \mathrm{~nm}$ (blue); C) D), and E) show a magnification of the $5 \mathrm{D}_{0} \rightarrow 7 \mathrm{~F}_{0-2}$ transitions in $\mathrm{A}$ ). (For interpretation of the references to color in this figure legend, the reader is referred to the web version of this article).

The room-temperature ${ }^{5} \mathrm{D}_{0}$ emission decay curves, monitored within the ${ }^{5} \mathrm{D}_{0} \rightarrow{ }^{7} \mathrm{~F}_{2}$ transition at 612 $\mathrm{nm}$ and excited at $270 \mathrm{~nm}$ are well-fitted by a single-exponential function (Figure S6, Table 2). In the solid state, $\mathrm{b}$-Eu and FSb-Eu present similar lifetime values, ca. $\tau=0.345 \pm 0.006 \mathrm{~ms}$. This is because the b-Eu complex is simply imbedded in the silica shell of FS NP, with no covalent 
interactions. Interestingly, in suspension both b-Eu complex and FSb-Eu NPs present a higher lifetime.

${ }^{5} \mathrm{D}_{0}$ radiative $\left(A_{r}\right)$ and non-radiative $\left(A_{n r}\right)$ transition probabilities are calculated after reference $\mathrm{e}^{27}$ (with $\tau^{-1}=A_{r}+A_{n r}$ ), respectively $1.06 \mathrm{~ms}^{-1}$ and $1.84 \mathrm{~ms}^{-1}$, for sample $\mathrm{FSb}-\mathrm{Eu}$ in the solid state. Comparing these values with those of the b-Eu complex $\left(A_{r}=0.56 \mathrm{~ms}^{-1}\right.$ and $A_{n r}=2.34 \mathrm{~ms}^{-1}$, Table S1 and Figure S5), a two-fold increase is observed in the radiative transition probability rate, and a 1.3-fold decrease in the non-radiative transition probability. Moreover, the corresponding quantum efficiency values, $\left(\eta=A_{r} /\left(A_{r}+A_{n r}\right)\right.$, are 0.37 and 0.19 for the nanoparticles and the complex, respectively. Both $\tau$ and $\eta$ compare well with literature values. ${ }^{28}$ The absolute solid-state emission quantum yields of FSb-Eu were measured for distinct excitation wavelengths. The maximum value, 0.01 at $310 \mathrm{~nm}$, is much lower than the value of the b-Eu complex $(0.20$ at 375 $\mathrm{nm}^{29}$ ), indicating a lower ligand-to-metal energy transfer efficiency following complex incorporation.

The number of water molecules coordinated to the $\mathrm{Eu}^{3+}$ ions $\left(\mathrm{n}_{\mathrm{w}}\right)$ was calculated based on the empirical formula: ${ }^{28}$

$n_{w}=1.11 \times\left(\frac{1}{\tau_{E X P}}-\frac{1}{\tau_{R A D}}-0.31\right)$

The values obtained for, respectively, FSb-Eu NP and the b-Eu complex were, respectively, 1.7 and 2.3, i.e., 2 within the experimental error (Table S1). The fact that the metal coordination number does not change suggests the surface $\mathrm{Si}-\mathrm{OH}$ groups do not coordinate to the $\mathrm{Eu}^{3+}$ ions, rather they hydrogen-bond to the water molecules coordinated to the metal.

The emission spectra of FSb-EuGd (Figure S7) gave results similar to those described above, showing that the $\mathrm{Eu}^{3+}$ emission features are not influenced by the $\mathrm{Gd}^{3+}$ incorporation. 

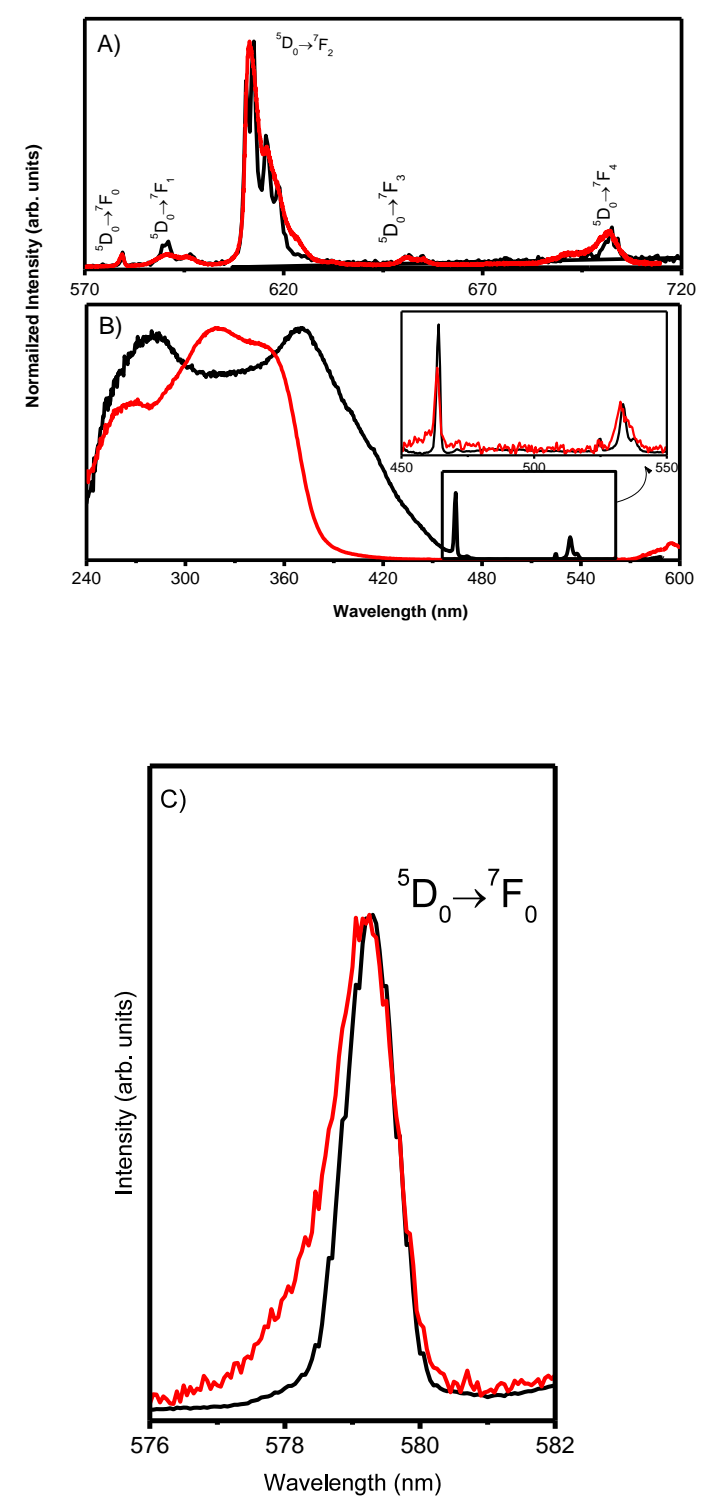

Figure 3: A) Emission spectra (300K) of b-Eu, (black) and FSb-Eu, (red) both excited at $270 \mathrm{~nm}$; B) Excitation spectra (300K) of b-Eu (black) and FSb-Eu (red), monitored at $612 \mathrm{~nm}$; C) Expanded ${ }^{5} \mathrm{D}_{0} \rightarrow{ }^{7} \mathrm{~F}_{0}$ transition for estimation of its FWHM in the complex form b-Eu (black) and NP FSb$\mathrm{Eu}$, (red) (For interpretation of the references to color in this figure legend, the reader is referred to the web version of this article). 
Table 2. ${ }^{5} \mathrm{D}_{0}$ decay times of samples monitored at $612 \mathrm{~nm}$ and excited at $270 \mathrm{~nm}$, at $300 \mathrm{~K}$.

\begin{tabular}{lll}
\hline Nanoparticles & Physical state & $\tau(\mathrm{ms})$ \\
\hline b-Eu & Solid & $0.345 \pm 0.006$ \\
b-Eu & suspension & $0.610 \pm 0.012$ \\
FSb-Eu & Solid & $0.345 \pm 0.006$ \\
FSb-Eu & suspension & $0.642 \pm 0.012$ \\
\hline
\end{tabular}

\section{Magnetization and relaxivity properties}

The magnetic properties of the nanosystems were evaluated by field-dependent magnetization measurements at 298 K (Figure S8). All systems showed a typical superparamagnetic behavior and hysteresis loops in the $M(H)$ curves with the typical Langevin-like shape. Fitting the experimental $M(H)$ curves yielded calculated saturation magnetization values $\left(M_{S}\right)$ (per $\mathrm{g}$ of $\mathrm{Fe}$ ) of 62.1, 57.4, 55.4 and 55.2 $\mathrm{emu} \cdot \mathrm{g}^{-1}$ for F NPs, FS NPs, FSb-Gd and FSb-EuGd, respectively. The absence of coercivity, and the size of the NPs evidence the presence of superparamagnetism. The $M_{S}$ value obtained for bare $\mathrm{F}$ at $298 \mathrm{~K}$ is lower than the typical value for bulk maghemite (78 emu $\left.\cdot \mathrm{g}^{-1}\right) .{ }^{30}$ The $M_{S}$ value of FS is smaller than the value of F, presumably due to induced spin canting at the core-silica coating interface. ${ }^{31}$ The slight further reduction of $M_{S}$ for FSb-Gd and FSb-EuGd indicates that the diamagnetic contribution from the inserted complexes fully counterbalances the $\mathrm{Gd}^{3+}$ and $\mathrm{Eu}^{3+}$ paramagnetic contribution. This is confirmed by the absence of a paramagnetic contribution to their $M(H)$ curves, which would be visible at very low and very high magnetic fields.

The NPs are well dispersed in water, and the suspensions remained stable for at least 24 hours, allowing the collection of consistent water proton relaxation data, and the evaluation of their in vitro potential as MRI contrast agents. Figure 4 shows representative $T_{1}$ - and $T_{2}$-weighted nuclear 
magnetic resonance phantom images recorded at $9.4 \mathrm{~T}$ of $\mathrm{b}-\mathrm{Gd}$ aqueous solutions, and suspensions of FSb-Gd and FSb-EuGd, at increasing $\mathrm{Gd}^{3+}$ and $\mathrm{Fe}^{3+}$ concentrations. The $r_{1}$ and $r_{2}$ relaxivity values are collected in Table 3, and representative plots are shown in Figure $\mathbf{4} \mathbf{C}$ and $\mathbf{D}$, respectively. These values were calculated from the observed linear dependence of the $R_{i}\left(=1 / T_{i}, \mathrm{i}\right.$ $=1,2$ ) relaxation rates on the concentration of the $\mathrm{Gd}^{3+}$ or $\mathrm{Fe}^{3+}$ ions (Equation 1), using at least five different concentrations.

Table 3. Water ${ }^{1} \mathrm{H}$ relaxivities, $r_{i}(i=1$, 2) $(9.4 \mathrm{~T}, 400 \mathrm{MHz}, 298 \mathrm{~K})$, for the $b-G d$ complex and aqueous suspensions of FS NPs, FSb-Gd, and FSb-EuGd NPs.

\begin{tabular}{|c|c|c|c|}
\hline Sample & $r_{l}\left(\mathrm{mM}^{-1} \cdot \mathrm{s}^{-1}\right)$ & $r_{2}\left(\mathrm{mM}^{-1} \cdot \mathrm{s}^{-1}\right)$ & $r_{2} / r_{1}$ \\
\hline $\mathrm{FS}$ & $0.8 \pm 0.1^{\mathrm{a}}$ & $89 \pm 2^{a}$ & 111 \\
\hline b-Gd & $6.5 \pm 0.4^{b}$ & $7.8 \pm 0.5^{b}$ & 1.2 \\
\hline $\mathrm{b}-\mathrm{Eu}$ & $1.9 \pm 0.4^{\mathrm{c}}$ & $4.8 \pm 0.6^{c}$ & 2.5 \\
\hline \multirow[t]{3}{*}{ FSb-Gd } & $27.2 \pm 0.2^{\mathrm{b}}$ & $2930 \pm 30^{\mathrm{b}}$ & 108 \\
\hline & $0.8 \pm 0.2^{\mathrm{a}}$ & $77.8 \pm 0.3^{\mathrm{a}}$ & 97 \\
\hline & $1.0 \pm 0.5^{\mathrm{d}}$ & $75.9 \pm 0.3^{\mathrm{d}}$ & 78 \\
\hline \multirow[t]{3}{*}{ FSb-EuGd } & $38.8 \pm 0.2^{\mathrm{e}}$ & $1681 \pm 3^{e}$ & 43 \\
\hline & $1.0 \pm 0.2^{\mathrm{a}}$ & $44.6 \pm 0.3^{a}$ & 45 \\
\hline & $1.0 \pm 0.2^{\mathrm{f}}$ & $43.4 \pm 0.6^{\mathrm{f}}$ & 44 \\
\hline
\end{tabular}

The relaxivities of the b-Gd complex and the Gd-bearing NPs have contributions from the innersphere (IS) and outer-sphere (OS) mechanisms. ${ }^{2-3,12,32}$ For small complexes like b-Gd, the IS contribution depends mainly on the hydration number $(q)$, the rotational correlation time $\left(\tau_{R}\right)$, the water exchange rate $\left(k_{e x}\right)$ and the electron spin relaxation times $\left(T_{1,2 e}\right)$ of the $\mathrm{Gd}^{3+}$ ion according to the Solomon-Bloembergen-Morgan (SBM) theory, while the OS contribution depends on the selfdiffusion constants of the water and complex molecules and on their distance of closest approach, according to the Freed theory. ${ }^{1-2}$ All Gd-containing systems induce a bright signal enhancement in 
a concentration-dependent manner on the $T_{1}$-weighted images (Figure 4A). The $r_{1}=6.5 \mathrm{~m}^{-1} \mathrm{~s}^{-1}$ observed for b-Gd is comparable to $r_{l}$ values $\left(20 \mathrm{MHz}, 25^{\circ} \mathrm{C}\right)=7.1-10.5 \mathrm{~m}^{-1} \cdot \mathrm{s}^{-1}$ reported for small $\mathrm{Gd}^{3+}$ complexes with $q=2$ and high $k_{e x}$ values $\left(1-5.3 \times 10^{7} \mathrm{~s}^{-1}\right),{ }^{2-3,12,32-34}$ and is higher than the value reported for the clinically used $\left[\mathrm{Gd}(\mathrm{DTPA}]^{2-}\right.$ complex, Magnevist $\left(r_{1}=3.9 \mathrm{~m}_{\mathrm{M}}^{-1} \cdot \mathrm{s}^{-1}\right)$, at the same. 

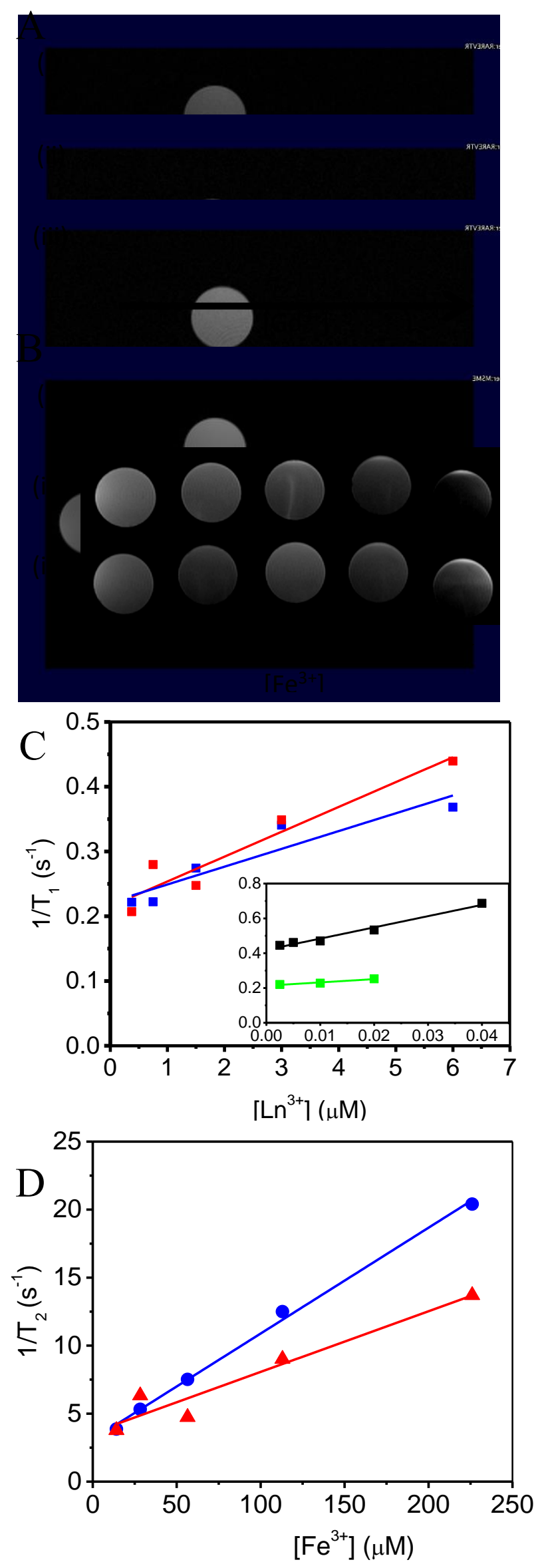
Figure 4: $\mathrm{T}_{1}$-weighted (A) and $\mathrm{T}_{2}$-weighted (B) nuclear magnetic resonance images of aqueous solutions of (i) b-Gd, (ii) FSb-Gd, and (iii) FSb-EuGd, as a function of $\mathrm{Gd}^{3+}$ and $\mathrm{Fe}^{3+}$ concentrations $\left(\mathrm{T}_{1}\right.$-weighted images: repetition time $=450 \mathrm{~ms}$, echo time $12 \mathrm{~ms} ; \mathrm{T}_{2}$-weighted images: repetition time $=4000 \mathrm{~ms}$, echo time $80 \mathrm{~ms}$ ). Longitudinal $(\mathrm{C})$ and transverse (D)

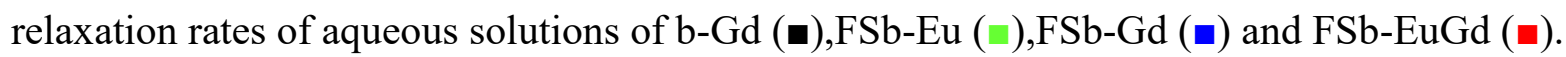

For Ln-containing NPs, the IS mechanism results from the water molecules directly coordinated to the $\mathrm{Ln}^{3+}$ ions on the surface of the NPs that, for $\mathrm{Gd}^{3+}$, affect the proton relaxation through contact and dipolar terms, and for $\mathrm{Eu}^{3+}$ also via a Curie term. ${ }^{35}$ The $r_{1}$ value depends on the hydration number of the surface ions, and the NPs surface-to-volume ratio. ${ }^{5,36}$ The OS mechanism results from the diffusion of the water molecules in the magnetic field inhomogeneities created by the magnetized NPs in their vicinity, and does not contain the contact term. It depends on their distance of closest approach to the NPs surface, and on the NPs size and magnetization. ${ }^{5,36}$ The contribution of the $\mathrm{Fe}^{3+}$ ions in the superparamagnetic iron oxide core contribution has been described. ${ }^{5}$

In the case of the Gd-containing NPs, the OS contribution of the iron oxide core to $r_{l}$ is expected to be negligible relative to the contribution of the $\mathrm{Gd}^{3+}$ ions, as suggested by the extremely low FS NP value $r_{1}=0.8 \mathrm{~m}^{-1} \cdot \mathrm{s}^{-1}$ referred to Fe. The large $r_{l}$ value $\left(27.2 \mathrm{~m}^{-1} \cdot \mathrm{s}^{-1}\right.$ referred to Gd $)$ obtained for FSb-Gd stems from the slow rotational diffusion (longer $\tau_{R}$ ) of the b-Gd complex due to its immobilization on the silica shell, as previously observed for protein bound complexes. ${ }^{2-3,37}$ The small decrease of the inner-sphere $q$ value expected from the value $q=1.7$ obtained for the embedded $\mathrm{Eu}^{3+}$ complex may be compensated by the efficient exchange with bulk water, and possible accessibility of the second sphere water molecules due to the porosity of the silica shell to water. ${ }^{38}$ For FSb-EuGd, where $50 \%$ of the btfa-coordinated $\mathrm{Gd}^{3+}$ ions are replaced by $\mathrm{Eu}^{3+}$, the 
observed increase of $r_{I}\left(38.8 \mathrm{mM}^{-1} \cdot \mathrm{s}^{-1}\right)$ relative to FSb-Gd reflects the Curie spin relaxation contribution of the $\mathrm{Eu}^{3+}$ ions, expected at high magnetic fields and long $\tau_{R}$ values, when the correlation time for the dipolar coupling described by the SBM equations is governed by the electronic relaxation times, which is the case for $\mathrm{Eu}^{3+} .35$

Regarding the $T_{2}$-weighted images (Figure 4B), the b-Gd complex and the Gd-labeled NPs also display a significant signal reduction with increasing Gd or Fe concentration. The $r_{2}$ values of all NPs (Table 3) are considerably higher than $r_{1}$, giving $r_{2} / r_{1}$ values much larger than 2 , corresponding to a dominant $T_{2}$-weighted (negative-contrast) mechanism. These effects are dominated by the iron oxide core OS contribution to $r_{2}$, as indicated by the large FFS $r_{2}$ value observed. The NPs $r_{2}$ values decrease from $89 \mathrm{~m}^{-1} \cdot \mathrm{s}^{-1}$ for FS to 77.8 or $44.6 \mathrm{~m}^{-1} \mathrm{~s}^{-1}$ after embedding the $\mathrm{Gd}^{3+}$ and $\mathrm{Eu}^{3+} / \mathrm{Gd}^{3+}$ complexes (FSb-Gd and FSb-EuGd, respectively). Such decrease ( $87 \%$ and $50 \%$ of the original values) cannot be attributed to the reduced saturation magnetization $\left(M_{S}\right)$ of the particles, which are only reduced to $96 \%$ of the original values. ${ }^{39}$ Therefore, they strongly suggest that the paramagnetic $\mathrm{Gd}^{3+}$ or $\mathrm{Eu}^{3+}$ chelates have a negative impact on the $T_{2}$ relaxation process of the superparamagnetic magnetite core, in agreement with their position outside the iron oxide core. ${ }^{40-50}$ Although the present NPs have lower $r_{2}$ values than PEGylated SPION particles $(10.6 \mathrm{~nm})\left(79.2 \mathrm{~m}^{-1} \cdot \mathrm{s}^{-1}, 9.4 \mathrm{~T}\right)^{51}$, possibly due to the higher water permeability of the PEG corona relative to the silica shell, their $T_{2}$ contrast effect was sufficiently strong to produce a negative contrast enhancement of the phantom images.

\section{Internalization and cytotoxicity of NPs}

The cellular internalization and cytotoxicity of the three Ln-loaded core-shell nanosystems were evaluated. ICP-MS was used to quantify the amounts of NPs internalized by Hela cells after 
different exposure times (2, 4 and 6 hours) to $50 \mu \mathrm{g} / \mathrm{mL}$ NPs (Figure S9). The results indicate a time-dependent increase of the uptake of the NPs by Hela cells, with similar internalization kinetics for the three types of NPs. After 4 hours, all systems presented the same internalization efficiency and, thus, this time interval was adopted in the subsequent cytotoxicity and cell imaging studies. The NPs uptake did cause changes in the cell morphology, which were only observed after a few hours of exposure, suggesting interference with normal cell function. A preliminary biological effect assessment was carried out by exposing Hela cells $\left(7 \times 10^{3}\right.$ cell/well $)$ to increasing NPs concentrations $(10-125 \mu \mathrm{g} / \mathrm{mL})$ for 24 and 48 hours. Reduction of ATP levels is considered a reliable cell viability marker. ${ }^{52}$ Cell metabolism was assessed by ATP production using a CellTiter-Glo® Cell Viability Assay. Figure S10 shows a decrease in ATP content of Hela cells upon increase of the concentration of NPs. Concentrations equal or higher than $125 \mu \mathrm{g} / \mathrm{mL}$ resulted in a significant impairment of the ATP production relative to the control for 24 and 48 hours $(\mathrm{P}<$ 0.0001 or $\mathrm{P}<0.001)$. Similar results were also reported for iron oxide NPs coated with silica. ${ }^{53}$ For concentrations lower than $62.5 \mu \mathrm{g} / \mathrm{mL}$, the ATP production showed no significant changes with respect to the controls for the three types of NPs (except for FSb-Gd after the first 24 hours; however, after 48 hours the cells had recovered a normal ATP production). Thus, this preliminary test indicates the NPs are not cytotoxic to Hela cells at concentrations below $62.5 \mu \mathrm{g} / \mathrm{mL}$. Further tests should be performed to assess in more detail the NPs cytotoxicity to other cell lines. Nevertheless, the full viability of Hela cells was ensured for the concentration of $50 \mu \mathrm{g} / \mathrm{mL}$ used in our imaging studies. 


\section{Optical and Nuclear Magnetic Resonance imaging of cells}

Further insight into the cellular internalization of the NPs was gained by confocal microscopy (Figure 5A), that enabled their observation within the cells as blue dots in the merged micrographs. Confocal images show that both types of NPs containing $\mathrm{Eu}^{3+}$ ions are evenly distributed in the cytosol. Some particles form aggregates appearing as large and strongly fluorescent spots. To quantify the differences in cell uptake, the fluorescence intensity of each NP entereing the cell was estimated by calculating the mean fluorescence value per cell in the same area (Figure 5B).

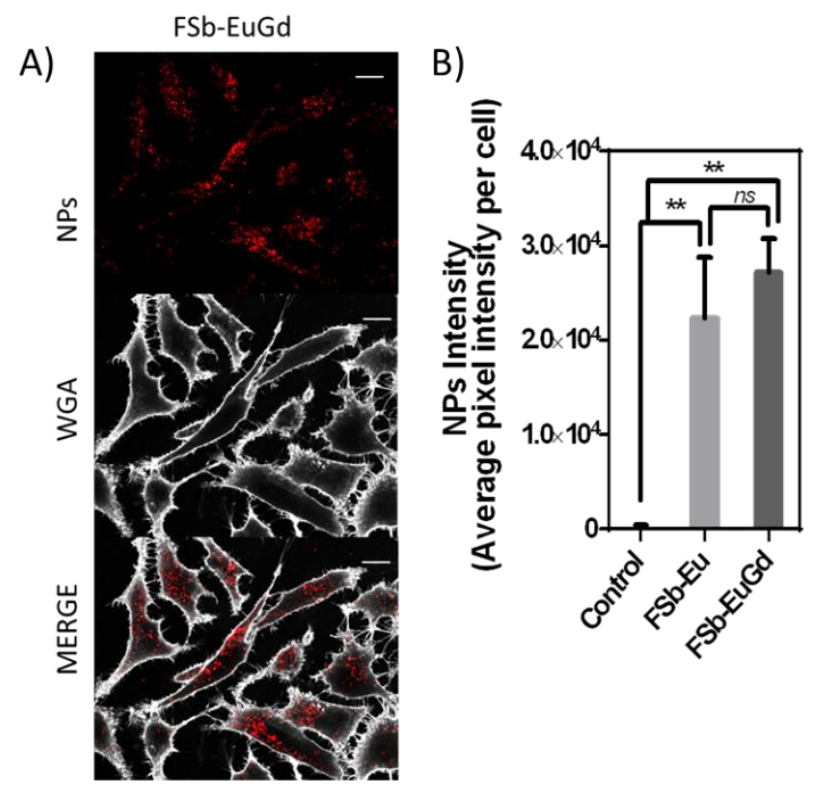

Figure 5: (A) Confocal microscopy images of FSbEu-Gd NPs-treated Hela cells; (B) Relative fluorescence intensity of each sample represented as the mean value/cell. The three different types of NPs were tested in each experiment, and 10-20 cells per experiment (total 30-60 cells) were randomly selected for imaging analysis. Results are presented as mean $\pm \mathrm{SD}(\mathrm{n}=3) .{ }^{* *}$ denote data points that are statistically significant compared with each other by one-way ANOVA at $95 \%$ confidence interval. 
As expected, FSb-Gd NPs could not be observed. Nevertheless, no statistically significant difference was found between FSb-Eu and FSb-EuGd, as expected. In general, the intracellular NPs fate is strongly affected by the entry route. Several endocytic pathways are known, namely: clathrin-mediated endocytosis, caveolae-mediated endocytosis, macropinocytosis, and clathrinand caveolae-independent endocytosis. ${ }^{52-53}$ The identification of these pathways is vital for understanding NPs fate but is beyond the scope of the present work. In conclusion, $\mathrm{Eu}^{3+}$-containing NPs FSb-Eu and FSb-EuGd can be used as fluorescent probes for cell imaging.

Finally, the suitability of b-Gd complex, FSb-Gd and FSb-EuGd NPs as $T_{1}-T_{2}$ multimodal contrast agents was also investigated at $9.4 \mathrm{~T}(400 \mathrm{MHz})$ using phantoms of pelleted labeled Hela cells (Figure 6). b-Gd complex and FS NPs were used as reference samples to evaluate the simultaneous $T_{1}$ and $T_{2}$ contrast capabilities of the lanthanide-bearing NPs, respectively. As expected, the cells labeled with the b-Gd complex appear as bright regions in the $T_{1}$-weighted images, indicating a strong positive contrast. However, a negative contrast effect was not observed in the $T_{2}$-weighted image, in agreement with the $r_{2} / r_{1}=1.2$ value. As expected, a dark signal was observed for the cells incubated with FS, witnessing a strong negative $T_{2}$ contrast, but no $T_{1}$ contrast effect, in accord with the very large $r_{2} / r_{1}=111$.

Cells labeled with FSb-Gd display a bright signal enhancement in the $T_{1}$-weighted image, although not as strong as observed in the presence of the b-Gd complex, as could be expected from their relative $r_{l}$ values (Table 3). This may be due to a higher cell uptake of b-Gd. FSb-Gd NPs also originate a marked signal drop on the $T_{2}$-weighted image, whose intensity is similar to FS NPs. FSb-EuGd induced a higher positive contrast effect, and a negative contrast effect on the cell samples, compared to FSb-Gd NPs, in accord with their $r_{l}$ and $r_{2} / r_{l}$ values. 
The above results demonstrate that FSb-Gd and FSb-EuGd NPs produce both a positive and negative contrast enhancement on the nuclear magnetic resonance images.

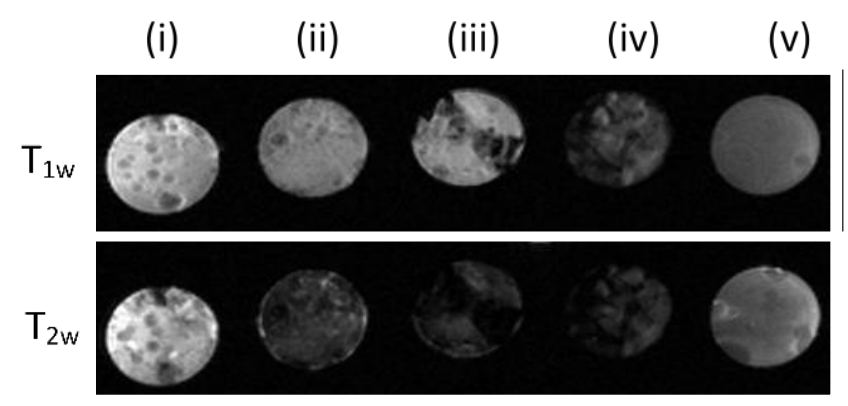

Figure 6: $T_{1}$ - and $T_{2}$-weighted nuclear magnetic resonance images of cellular pellet phantoms (i) cells + b-Gd, (ii) cells + FSb-Gd, (iii) cells + FSb-EuGd (iv) cells + FS NP and (v) control: cells ( $T_{1}$-weighted images: repetition time $=450 \mathrm{~ms}$, echo time $12 \mathrm{~ms} ; T_{2}$-weighted images: repetition time $=4000 \mathrm{~ms}$, echo time $80 \mathrm{~ms}$.

\section{CONCLUSIONS}

Superparamagnetic maghemite core-porous silica shell NPs FSb-Gd and FSb-EuGd (1:1 $\mathrm{Eu} / \mathrm{Gd}), 50 \mathrm{~nm}$ in diameter and with a $10 \mathrm{~nm}$ core size, containing paramagnetic b-Ln $(\mathrm{Ln}=\mathrm{Gd}$, $\mathrm{Eu}$ ) complexes evenly distributed in the shell have been reported. Due to their negative zeta potential, these NPs form stable water suspensions, and show no significant leaching of $\mathrm{Gd}^{3+}$ ions. FSb-Eu NPs labelled with the $\mathrm{Eu}^{3+}$ complexes in the absence of the corresponding $\mathrm{Gd}^{3+}$ complexes exhibit good luminescent properties, with a quantum efficiency three times larger than the free $\mathrm{Eu}^{3+}$ complex in solution. The latter properties are not deteriorated by further incorporation of 
$\mathrm{Gd}^{3+}$ complexes in the FSb-EuGd system. Incorporation of such complexes causes only a $4 \%$ decrease of the saturation magnetization $\left(M_{S}\right)$ relatively to the original FSb NPs, due to negligible spin canting effects. This is important, as $M_{S}$ is a factor determining the $r_{2}$ relaxivities.

FSb-Gd and FSb-EuGd NPs show $r_{l}$ values larger than the reference b-Gd complex in solution due to both, the direct accessibility of the complexes embedded in the silica pores to the water molecules, and the slow tumbling of the NPs modulating the dipole-dipole and Curie spin relaxation mechanisms. They have slightly lower $r_{2}$ values than the reference FS NPs, but their $r_{2} / r_{l}$ values are still high. The negative interference observed between the paramagnetic materials and the superparamagnetic magnetite core, resulting from the magnetic coupling with the longrange magnetic field produced by the core, which decreases the observed $r_{2}$ values, results from the location of the paramagnetic material outside the iron oxide core. ${ }^{40-50} \mathrm{~A}$ synergistic $T_{1}-T_{2}$ relaxation enhancement effect would be expected if the paramagnetic material were located inside the superparamagnetic iron oxide core. ${ }^{23,50,54-56}$

Hela cells efficiently and swiftly internalize FSb-EuGd NPs that reside in the cytosol. No cytotoxicity was observed at cell concentrations lower than $62.5 \mu \mathrm{g} \mathrm{mL} L^{-1} . T_{1}$ and $T_{2}$-weighted nuclear magnetic resonance studies of the labeled Hela cells showed that FSb-Gd and FSb-EuGd are better $T_{l}$ (positive) contrast agents than the b-Gd complex, and they are as efficient as FS NPs as $T_{2}$ (negative) contrast agents. A further advantage of the in vivo use of $\mathrm{Ln}^{3+}$-labelled NPs is their magnetic susceptibility, which causes negative contrast proportional to the magnetic moments but does not correlate with the $r_{l}$ values. ${ }^{36}$ Such effects have been reported in animal brain studies during infusion with $[\mathrm{Dy}(\mathrm{DTPA})]^{2-}$, resulting from the difference in magnetic susceptibility between the capillaries, containing the contrast agent, and the surrounding tissue. ${ }^{57}$ 
The shell embedding of isostructural $b$-Eu and $b$-Gd complexes in a 1:1 mole ratio in the FSbEuGd NPs improves the $T_{1}$ contrast capacity, without compromising its $T_{2}$ contrast. This nanosystem also exhibits important optical properties, affording useful trimodal $T_{1}-T_{2}$ nuclear magnetic resonance and optical imaging contrast agents of cells and tissues, or for in pre-clinical animal studies.

\section{Supporting Information}

The Supporting Information is available free of charge on the ACS Publications website at DOI: 10.1021/acs.inorgchem.

Scheme S1: Structure of the btfa ligand; Figure S1: A) TEM images showing the average size (diameter d) of the i) core F-NPs $\left(\gamma-\mathrm{Fe}_{2} \mathrm{O}_{3}\right)$ and ii) core-shell FS-NPs $\left(\gamma-\mathrm{Fe}_{2} \mathrm{O}_{3} @ \mathrm{SiO}_{2}\right)$. NPs B) histograms with experimental size distributions of samples i) core F-NPs and ii) core-shell FS-NPs $\left(\mathrm{\gamma}-\mathrm{Fe}_{2} \mathrm{O}_{3} @ \mathrm{SiO}_{2}\right)$ and corresponding calculated normal cumulative distributions for the specified mean and standard deviation; Figure S2: A) Calibration curve and the amount of free $\mathrm{Gd}^{3+}$ in 2 $\mathrm{mM}$ of fresh FSb-Gd aqueous dispersion sample; B) the corresponding UV-visible absorption spectra of xylenol orange solution $(18 \mu \mathrm{M})$ containing increasing concentrations of $\mathrm{Gd}^{3+}(0-70$ $\mu \mathrm{M}$ ); Figure S3 A) DRIFT spectra of the NPs: F-NP (black), $\mathrm{SiO}_{2}$ ( blue), FS-NP (orange), A) FNP (black) FSb-Eu (green) FSb-Gd (blue) and FSb-EuGd (red) c) F-NP (black) FSb-Eu (red) and bEu (green); Figure S4 Zeta potential titrations as a function of the $\mathrm{pH}$ of F-NP (black), FS-NP (red) and FSb-Ln, $(\mathrm{Ln}=\mathrm{Eu}, \mathrm{Gd}$ or $\mathrm{Eu} / \mathrm{Gd} 1: 1)$, (green) in aqueous suspensions; Figure S5: Emission spectra recorded at $300 \mathrm{~K}$ of FSb-Eu NPs in water suspension and in the solid state at two different wavelengths $270 \mathrm{~nm}$ and $310-320 \mathrm{~nm}$; Expanded ${ }^{5} \mathrm{D}_{0} \rightarrow{ }^{7} \mathrm{~F}_{0}$ transition of complex b$\mathrm{Eu}$ and FSb-Eu NPs in water suspensions; Figure S6: Emission decay curves $(300 \mathrm{~K})$ of the ${ }^{5} \mathrm{D}_{0}$ 
excited state of FSb-Eu, and b-Eu, monitored at $612 \mathrm{~nm}$ and excited at $270 \mathrm{~nm}$, in the solid state and aqueous suspension. The experimental decay curves were fitted to a single exponential decay (r2 > 0.99); Figure S7: A) Excitation spectrum (300 K) of FSb-EuGd (solid state) monitored at $612 \mathrm{~nm}$; B) Emission spectrum ( $300 \mathrm{~K}$ ) of FSb-Eu (solid state) excited at $270 \mathrm{~nm}$ and $310 \mathrm{~nm}$; Figure S8: Magnetization vs. applied magnetic field loops between - $150 \mathrm{kOe}$ and $+150 \mathrm{kOe}$ at 298 K for F-NP( $\bullet$ ),FS-NP (•),FSb-Gd ( $\mathbf{\Delta})$ and FSb-EuGd ( ); Figure S9: Quantification of FSbEu, FSb-Gd and FSb-EuGd NPs in Hela cells determined by ICP-MS; Figure S10: Effect of NPs on the metabolism of Hela cells incubated with FSb-Eu, FSb-Gd and FSb-EuGd) for $24 \mathrm{~h}$ and 48 h; Table S1: ${ }^{5} \mathrm{D}_{0}$ decay times of samples monitored at $612 \mathrm{~nm}$ and excited at $270 \mathrm{~nm}$, at $300 \mathrm{~K}(\tau)$; ${ }^{5} D_{0}$ radiative $\left(A_{r}\right)$ and non-radiative $\left(A_{n r}\right)$ transition probabilities are calculated after reference ${ }^{1}$ (with $\tau^{-1}=A_{r}+A_{n r}$ ); and the calculated number of water molecules in the coordination sphere of the $\mathrm{Eu}^{3+}$ ion (n).

\section{AUTHOR INFORMATION}

\section{Corresponding Author}

*E-mail: slpinho@uc-biotech.pt.

*E-mail: geraldes@uc.pt.

\section{ORCID}

Sonia L.C. Pinho: 0000-0003-1989-8976

Carlos F.G.C. Geraldes: 0000-0002-0837-8329 
Notes The authors declare no competing financial interest.

\section{ACKNOWLEDGMENTS}

This work was funded by FEDER through the Operational Program Competitiveness Factors -

COMPETE and national funds from FCT - Foundation for Science and Technology (PTDC/NAN-

MAT/28060/2017， CENTRO-01-0145-FEDER-028060， UID/QUI/00313/2013 and PEst-

OE/QUI/UI0313/2014) and UID/NEU/ 04539/ 2019, the CNRS, the Région Nouvelle Aquitaine

France, FEDER, COST Action D38 “Metal-Based systems for Molecular Imaging Applications”.

The work was developed in the scope of the project CICECO Aveiro Institute of Materials (FCT

Ref. UID/CTM/50011/2019), financed by national funds through FCT/MEC.

UID/QUI/00313/2013 and PEst-OE/QUI/UI0313/2014

\section{REFERENCES}

1. Principles of Magnetic Resonance Imaging: a Signal Processing Perspective [Book Review]. IEEE Signal Processing Magazine 2002, 19 (4), 86-87 DOI: 10.1109/msp.2002.1012356.

2. Merbach, A. E. H., L.; Tóth, É., The Chemistry of Contrast Agents in Medical Magnetic Resonance Imaging. Wiley: 2013.

3. Caravan, P.; Ellison, J. J.; McMurry, T. J.; Lauffer, R. B. Gadolinium(III) Chelates as MRI Contrast Agents: Structure, Dynamics, and Applications. Chemical Reviews 1999, 99 (9), 22932352 DOI: $10.1021 /$ cr980440x.

4. L. Villaraza, A. J.; Bumb, A.; Brechbiel, M. W. Macromolecules, Dendrimers, and Nanomaterials in Magnetic Resonance Imaging: The Interplay between Size, Function, and Pharmacokinetics. Chemical Reviews 2010, 110 (5), 2921-2959 DOI: 10.1021/cr900232t.

5. Laurent, S.; Forge, D.; Port, M.; Roch, A.; Robic, C.; Vander Elst, L.; Muller, R. N. Magnetic Iron Oxide Nanoparticles: Synthesis, Stabilization, Vectorization, Physicochemical Characterizations, and Biological Applications. Chemical Reviews 2008, 108 (6), 2064-2110 DOI: $10.1021 / \mathrm{cr} 068445 \mathrm{e}$.

6. Lee, N.; Hyeon, T. Designed Synthesis of Uniformly Sized Iron Oxide Nanoparticles for Efficient Magnetic Resonance Imaging Contrast Agents. Chemical Society Reviews 2012, 41 (7), 2575-2589 DOI: 10.1039/c1cs15248c.

7. Lee, N.; Yoo, D.; Ling, D.; Cho, M. H.; Hyeon, T.; Cheon, J. Iron Oxide Based Nanoparticles for Multimodal Imaging and Magnetoresponsive Therapy. Chemical Reviews 2015, 115 (19), 10637-10689 DOI: 10.1021/acs.chemrev.5b00112. 
8. Jun, Y.-w.; Seo, J.-w.; Cheon, J. Nanoscaling Laws of Magnetic Nanoparticles and Their Applicabilities in Biomedical Sciences. Accounts of Chemical Research 2008, 41 (2), 179-189 DOI: $10.1021 /$ ar700121f.

9. McCarthy, J. R.; Weissleder, R. Multifunctional Magnetic Nanoparticles for Targeted Imaging and Therapy. Advanced Drug Delivery Reviews 2008, 60 (11), 1241-1251 DOI: https://doi.org/10.1016/j.addr.2008.03.014.

10. Gao, J.; Gu, H.; Xu, B. Multifunctional Magnetic Nanoparticles: Design, Synthesis, and Biomedical Applications. Accounts of Chemical Research 2009, 42 (8), 1097-1107 DOI: 10.1021/ar9000026.

11. Zhang, L.; Liu, R.; Peng, H.; Li, P.; Xu, Z.; Whittaker, A. K. The Evolution of Gadolinium Based Contrast Agents: From Single-Modality to Multi-Modality. Nanoscale 2016, 8 (20), 1049110510 DOI: 10.1039/c6nr00267f.

12. Pinho, S. L. C.; Pereira, G. A.; Voisin, P.; Kassem, J.; Bouchaud, V.; Etienne, L.; Peters, J. A.; Carlos, L.; Mornet, S.; Geraldes, C. F. G. C.; Rocha, J.; Delville, M.-H. Fine Tuning of the Relaxometry of $\gamma-\mathrm{Fe}_{2} \mathrm{O}_{3} @ \mathrm{SiO}_{2}$ Nanoparticles by Tweaking the Silica Coating Thickness. ACS Nano 2010, 4 (9), 5339-5349 DOI: 10.1021/nn101129r.

13. Li, S.; Wan, Q.; Qin, Z.; Fu, Y.; Gu, Y. Understanding Stöber Silica's Pore Characteristics Measured by Gas Adsorption. Langmuir 2015, 31 (2), 824-832 DOI: 10.1021/la5042103.

14. Stöber, W.; Fink, A.; Bohn, E. Controlled Growth of Monodisperse Silica Spheres in the Micron Size Range. Journal of Colloid and Interface Science 1968, 26 (1), 62-69 DOI: https://doi.org/10.1016/0021-9797(68)90272-5.

15. Chen, S.-L.; Dong, P.; Yang, G.-H.; Yang, J.-J. Characteristic Aspects of Formation of New Particles During the Growth of Monosize Silica Seeds. Journal of Colloid and Interface Science 1996, 180 (1), 237-241 DOI: https://doi.org/10.1006/jcis.1996.0295.

16. Fernandes, M.; Nobre, S. S.; Gonçalves, M. C.; Charas, A.; Morgado, J.; Ferreira, R. A. S.; Carlos, L. D.; de Zea Bermudez, V. Dual role of a di-urethanesil Hybrid Doped with Europium $\beta$-diketonate Complexes Containing Either Water Ligands or a Bulky Chelating Ligand. Journal of Materials Chemistry 2009, 19 (6), 733-742 DOI: 10.1039/b813155d.

17. Barge, A.; Cravotto, G.; Gianolio, E.; Fedeli, F. How to Determine Free Gd and Free Ligand in Solution of Gd Chelates. A Technical Note. Contrast Media \& Molecular Imaging 2006, 1 (5), 184-188 DOI: doi:10.1002/cmmi.110.

18. Debasu, M. L.; Ananias, D.; Pinho, S. L. C.; Geraldes, C. F. G. C.; Carlos, L. D.; Rocha, J. $(\mathrm{Gd}, \mathrm{Yb}, \mathrm{Tb}) \mathrm{PO}_{4}$ Up-conversion Nanocrystals for Bimodal Luminescence-MR Imaging. Nanoscale 2012, 4 (16), 5154-5162 DOI: $10.1039 / \mathrm{c} 2 \mathrm{nr} 31226 \mathrm{c}$.

19. Alkilany, A. M.; Nagaria, P. K.; Hexel, C. R.; Shaw, T. J.; Murphy, C. J.; Wyatt, M. D. Cellular Uptake and Cytotoxicity of Gold Nanorods: Molecular Origin of Cytotoxicity and Surface Effects. Small 2009, 5 (6), 701-708 DOI: doi:10.1002/smll.200801546.

20. Lu, Y.; Yin, Y.; Mayers, B. T.; Xia, Y. Modifying the Surface Properties of Superparamagnetic Iron Oxide Nanoparticles through A Sol-Gel Approach. Nano Letters 2002, 2 (3), 183-186 DOI: $10.1021 / \mathrm{nl} 015681 \mathrm{q}$.

21. Mozaffari, M.; Shatooti, S.; Jafarzadeh, M.; Niyaifar, M.; Aftabi, A.; Mohammadpour, H.; Amiri, S. Synthesis of $\mathrm{Zn}^{2+}$ Substituted Maghemite Nanoparticles and Investigation of their Structural and Magnetic Properties. Journal of Magnetism and Magnetic Materials 2015, 382, 366-375 DOI: https://doi.org/10.1016/j.jmmm.2015.01.087.

22. Miller, F. A.; Wilkins, C. H. Infrared Spectra and Characteristic Frequencies of Inorganic Ions. Analytical Chemistry 1952, 24 (8), 1253-1294 DOI: 10.1021/ac60068a007. 
23. Li, Z.; Yi, P. W.; Sun, Q.; Lei, H.; Li Zhao, H.; Zhu, Z. H.; Smith, S. C.; Lan, M. B.; Lu, G. Q. Ultrasmall Water-Soluble and Biocompatible Magnetic Iron Oxide Nanoparticles as Positive and Negative Dual Contrast Agents. Advanced Functional Materials 2012, 22 (11), 2387-2393 DOI: doi:10.1002/adfm.201103123.

24. Brinker, C. S., G. Sol-Gel Science: The Physics and Chemistry of Sol-Gel Processing. Academic 1990, chapter 9, 908.

25. Voisin, P.; Ribot, E. J.; Miraux, S.; Bouzier-Sore, A.-K.; Lahitte, J.-F.; Bouchaud, V.; Mornet, S.; Thiaudiere, E.; Franconi, J.-M.; Raison, L.; Labrugere, C.; Delville, M.-H. Use of Lanthanide-Grafted Inorganic Nanoparticles as Effective Contrast Agents for Cellular Uptake Imaging. Bioconjugate Chemistry 2007, 18 (4), 1053-1063 DOI: 10.1021/bc060269t.

26. Todd, D. J.; Kay, J. Gadolinium-Induced Fibrosis. Annual Review of Medicine 2016, 67 (1), 273-291 DOI: 10.1146/annurev-med-063014-124936.

27. Carlos, L. D.; Ferreira, R. A. S.; Bermudez, V. d. Z.; Ribeiro, S. J. L. LanthanideContaining Light-Emitting Organic-Inorganic Hybrids: A Bet on the Future. Advanced materials 2009, 21 (5), 509-534 DOI: 10.1002/adma.200801635.

28. Lima, N. B. D.; Gonçalves, S. M. C.; Júnior, S. A.; Simas, A. M. A Comprehensive Strategy to Boost the Quantum Yield of Luminescence of Europium Complexes. Scientific Reports 2013, 3, 2395 DOI: 10.1038/srep02395.

29. Junior, S. A.; de Almeida, F. V.; de Sá, G. F.; de Mello Donegá, C. Luminescence and Quantum Yields of $\mathrm{Eu}^{3+}$ Mixed Complexes with 1-phenyl-1,3-butanedione and 1,10phenanthroline or 1,10-phenanthroline-N-oxide. Journal of Luminescence 1997, 72-74, 478-480 DOI: https://doi.org/10.1016/S0022-2313(97)00025-2.

30. Durdureanu-Angheluta, A.; Pricop, L.; Stoica, I.; Peptu, C.-A.; Dascalu, A.; Marangoci, N.; Doroftei, F.; Chiriac, H.; Pinteala, M.; Simionescu, B. C. Synthesis and Characterization of Magnetite Particles Covered with $\alpha$-trietoxysilil-polydimethylsiloxane. Journal of Magnetism and Magnetic Materials 2010, 322 (19), 2956-2968 DOI: 10.1016/j.jmmm.2010.05.013.

31. Cabrera, M. P.; Filho, P. E. C.; Silva, C. M. C. M.; Oliveira, R. M.; Geraldes, C. F. G. C.; Castro, M. M. C. A.; Costa, B. F. O.; Henriques, M. S. C.; Paixão, J. A.; Carvalho, L. B.; Santos, B. S.; Hallwass, F.; Fontes, A.; Pereira, G. A. L. Highly Fluorescent and Superparamagnetic Nanosystem for Biomedical Applications. Nanotechnology 2017, 28 (28), 285704 DOI: 10.1088/1361-6528/aa752a.

32. Xu, J.; Franklin, S. J.; Whisenhunt, D. W.; Raymond, K. N. Gadolinium Complex of Tris[(3-hydroxy-1-methyl- 2-oxo-1,2-didehydropyridine-4-carboxamido)ethyl]-amine: A New Class of Gadolinium Magnetic Resonance Relaxation Agents. Journal of the American Chemical Society 1995, 117 (27), 7245-7246 DOI: 10.1021/ja00132a025.

33. Ruloff, R.; Muller, R. N.; Pubanz, D.; Merbach, A. A Tripod Gadolinium (III) Poly(amino Carboxylate) Relevant to Magnetic Resonance Imaging: Structural and Dynamical ${ }^{17} \mathrm{O}$ NMR and ${ }^{1} \mathrm{H}$ NMRD Studies. Inorganica Chimica Acta 1998, 275-276, 15-23 DOI: 10.1016/S00201693(98)00080-2.

34. Aime, S.; Calabi, L.; Cavallotti, C.; Gianolio, E.; Giovenzana, G. B.; Losi, P.; Maiocchi, A.; Palmisano, G.; Sisti, M. [Gd-AAZTA]-: A New Structural Entry for an Improved Generation of MRI Contrast Agents. Inorganic Chemistry 2004, 43 (24), 7588-7590 DOI: 10.1021/ic0489692. 35. Bertini, I. L., C.; Parigi, G.; Ravera, E. . In NMR of Paramagnetic Molecules; Elsevier, A., Ed.; 2017. 
36. Norek, M.; Peters, J. A. MRI Contrast Agents Based on Dysprosium or Holmium. Progress in Nuclear Magnetic Resonance Spectroscopy 2011, 59 (1), 64-82 DOI: 10.1016/j.pnmrs.2010.08.002.

37. Turner, J. L.; Pan, D.; Plummer, R.; Chen, Z.; Whittaker, A. K.; Wooley, K. L. Synthesis of Gadolinium-Labeled Shell-Crosslinked Nanoparticles for Magnetic Resonance Imaging Applications. Advanced Functional Materials 2005, 15 (8), 1248-1254 DOI: 10.1002/adfm.200500005.

38. Pinho, S. L. C.; Laurent, S.; Rocha, J.; Roch, A.; Delville, M.-H.; Mornet, S.; Carlos, L. D.; Vander Elst, L.; Muller, R. N.; Geraldes, C. F. G. C. Relaxometric Studies of $\gamma-\mathrm{Fe}_{2} \mathrm{O}_{3} @ \mathrm{SiO}_{2}$ Core Shell Nanoparticles: When the Coating Matters. The Journal of Physical Chemistry C 2012, 116 (3), 2285-2291 DOI: 10.1021/jp2086413.

39. Jun, Y.-w.; Lee, J.-H.; Cheon, J. Chemical Design of Nanoparticle Probes for HighPerformance Magnetic Resonance Imaging. Angewandte Chemie International Edition 2008, 47 (28), 5122-5135 DOI: doi:10.1002/anie.200701674.

40. Choi, J.-S.; Lee, J.-H.; Shin, T.-H.; Song, H.-T.; Kim, E. Y.; Cheon, J. Self-Confirming “AND" Logic Nanoparticles for Fault-Free MRI. Journal of the American Chemical Society 2010, 132 (32), 11015-11017 DOI: 10.1021/ja104503g.

41. Im, G. H.; Kim, S. M.; Lee, D.-G.; Lee, W. J.; Lee, J. H.; Lee, I. S. $\mathrm{Fe}_{3} \mathrm{O}_{4} / \mathrm{MnO}$ Hybrid Nanocrystals as a Dual Contrast Agent for both $\mathrm{T}_{1}$ - and $\mathrm{T}_{2}$-Weighted Liver MRI. Biomaterials 2013, 34 (8), 2069-2076 DOI: https://doi.org/10.1016/j.biomaterials.2012.11.054.

42. Shin, T.-H.; Choi, J.-s.; Yun, S.; Kim, I.-S.; Song, H.-T.; Kim, Y.; Park, K. I.; Cheon, J. T1 and T2 Dual-Mode MRI Contrast Agent for Enhancing Accuracy by Engineered Nanomaterials. ACS Nano 2014, 8 (4), 3393-3401 DOI: 10.1021/nn405977t.

43. Li, F.; Zhi, D.; Luo, Y.; Zhang, J.; Nan, X.; Zhang, Y.; Zhou, W.; Qiu, B.; Wen, L.; Liang, G. Core/shell $\mathrm{Fe}_{3} \mathrm{O}_{4} / \mathrm{Gd}_{2} \mathrm{O}_{3}$ Nanocubes as $\mathrm{T}_{1}-\mathrm{T}_{2}$ Dual Modal MRI Contrast Agents. Nanoscale 2016, 8 (25), 12826-12833 DOI: 10.1039/c6nr02620f.

44. Bae, K. H.; Kim, Y. B.; Lee, Y.; Hwang, J.; Park, H.; Park, T. G. Bioinspired Synthesis and Characterization of Gadolinium-Labeled Magnetite Nanoparticles for Dual Contrast $\mathrm{T}_{1}$ - and $\mathrm{T}_{2}$-Weighted Magnetic Resonance Imaging. Bioconjugate Chemistry 2010, 21 (3), 505-512 DOI: $10.1021 / \mathrm{bc} 900424 \mathrm{u}$.

45. Li, H.; Li, Z.; Zhao, J.; Tang, B.; Chen, Y.; Hu, Y.; He, Z.; Wang, Y. Carboxymethyl Chitosan-Folic Acid-Conjugated $\mathrm{Fe}_{3} \mathrm{O}_{4} @ \mathrm{SiO}_{2}$ as a Safe and Targeting Antitumor Nanovehicle in vitro. Nanoscale Research Letters 2014, 9 (1), 146 DOI: 10.1186/1556-276x-9-146.

46. Yang, H.; Zhuang, Y.; Sun, Y.; Dai, A.; Shi, X.; Wu, D.; Li, F.; Hu, H.; Yang, S. Targeted ual-Contrast $\mathrm{T}_{1}$ - and $\mathrm{T}_{2}$-Weighted Magnetic Resonance Imaging of Tumors Using Multifunctional Gadolinium-Labeled Superparamagnetic Iron Oxide Nnanoparticles. Biomaterials 2011, 32 (20), 4584-4593 DOI: 10.1016/j.biomaterials.2011.03.018.

47. Keasberry, N. A.; Bañobre-López, M.; Wood, C.; Stasiuk, G. J.; Gallo, J.; Long, N. J. Tuning the Relaxation Rates of Dual-mode $\mathrm{T}_{1} / \mathrm{T}_{2}$ Nanoparticle Contrast Agents: a Study into the Ideal System. Nanoscale 2015, 7 (38), 16119-16128 DOI: 10.1039/c5nr04400f.

48. Wang, K.; An, L.; Tian, Q.; Lin, J.; Yang, S. Gadolinium-Labelled Iron/Iron Oxide Core/Shell Nanoparticles as $\mathrm{T}_{1}-\mathrm{T}_{2}$ Contrast Agent for Magnetic Resonance Imaging. RSC Advances 2018, 8 (47), 26764-26770 DOI: 10.1039/c8ra04530e.

49. Shen, J.; Li, Y.; Zhu, Y.; Yang, X.; Yao, X.; Li, J.; Huang, G.; Li, C. Multifunctional Gadolinium-Labeled Silica-Coated $\mathrm{Fe}_{3} \mathrm{O}_{4}$ and $\mathrm{CuInS}_{2}$ Nanoparticles as a Platform for in vivo Tri- 
Modality Magnetic Resonance and Fluorescence Imaging. Journal of Materials Chemistry B 2015, 3 (14), 2873-2882 DOI: 10.1039/c5tb00041f.

50. Yang, L.; Zhou, Z.; Liu, H.; Wu, C.; Zhang, H.; Huang, G.; Ai, H.; Gao, J. EuropiumEngineered Iron Oxide Nanocubes with High $T_{1}$ and $T_{2}$ Contrast Abilities for MRI in Living Subjects. Nanoscale 2015, 7 (15), 6843-6850 DOI: 10.1039/c5nr00774g.

51. Lassenberger, A.; Scheberl, A.; Stadlbauer, A.; Stiglbauer, A.; Helbich, T.; Reimhult, E. Individually Stabilized, Superparamagnetic Nanoparticles with Controlled Shell and Size Leading to Exceptional Stealth Properties and High Relaxivities. ACS applied materials \& interfaces 2017, 9 (4), 3343-3353 DOI: 10.1021/acsami.6b12932.

52. Conner, S. D.; Schmid, S. L. Regulated Portals of Entry into the Cell. Nature 2003, 422, 37 DOI: $10.1038 /$ nature 01451.

53. Johannes, L.; Lamaze, C. Clathrin-Dependent or Not: Is It Still the Question? Traffic 2002, 3 (7), 443-451 DOI: doi:10.1034/j.1600-0854.2002.30701.x.

54. Zhou, Z.; Huang, D.; Bao, J.; Chen, Q.; Liu, G.; Chen, Z.; Chen, X.; Gao, J. A Synergistically Enhanced $\mathrm{T}_{1}-\mathrm{T}_{2}$ Dual-Modal Contrast Agent. Advanced Materials 2012, 24 (46), 6223-6228 DOI: doi:10.1002/adma.201203169.

55. Zhou, Z.; Wang, L.; Chi, X.; Bao, J.; Yang, L.; Zhao, W.; Chen, Z.; Wang, X.; Chen, X.; Gao, J. Engineered Iron-Oxide-Based Nanoparticles as Enhanced $T_{1}$ Contrast Agents for Efficient Tumor Imaging. ACS nano 2013, 7 (4), 3287-3296 DOI: 10.1021/nn305991e.

56. $\quad$ Wang, X.; Zhou, Z.; Wang, Z.; Xue, Y.; Zeng, Y.; Gao, J.; Zhu, L.; Zhang, X.; Liu, G.; Chen, $X$. Gadolinium Embedded Iron Oxide Nanoclusters as $\mathrm{T}_{1}-\mathrm{T}_{2}$ Dual-Modal MRI-Visible Vectors for Safe and Efficient siRNA Delivery. Nanoscale 2013, 5 (17), 8098-8104 DOI: $10.1039 / \mathrm{c} 3 \mathrm{nr} 02797 \mathrm{j}$.

57. Villringer, A.; Rosen, B. R.; Belliveau, J. W.; Ackerman, J. L.; Lauffer, R. B.; Buxton, R. B.; Chao, Y.-S.; Wedeenand, V. J.; Brady, T. J. Dynamic Imaging With Lanthanide Chelates in Normal Brain: Contrast due to Magnetic Susceptibility Effects. Magnetic Resonance in Medicine 1988, 6 (2), 164-174 DOI: doi:10.1002/mrm.1910060205. 
For Table of Contents Only:

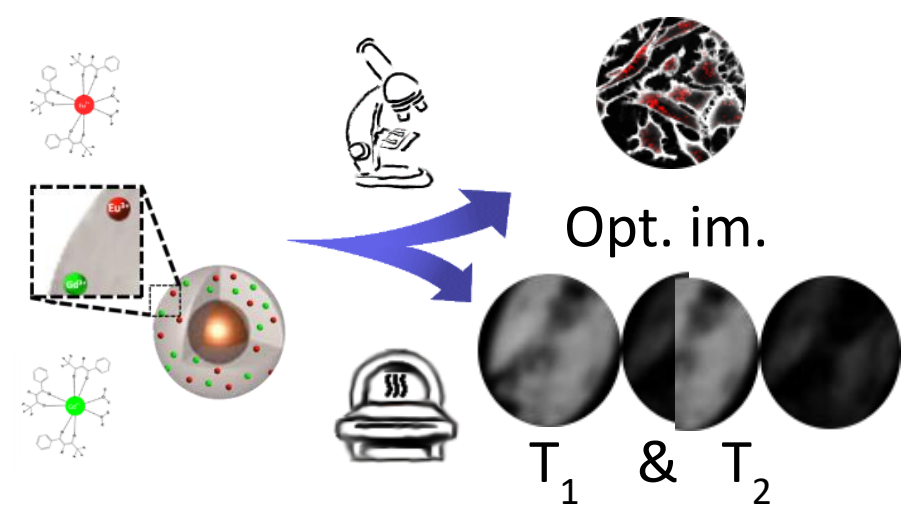

Table of Contents Synopsis: Water stable suspensions of superparamagnetic maghemite coremicroporous silica shell $50 \mathrm{~nm}$ NPs bearing paramagnetic $\mathrm{Ln}^{3+}$ complexes $(\mathrm{Ln}=\mathrm{Gd}, \mathrm{Eu})$ show promising $T_{1}-T_{2}$ MRI and optical imaging contrast properties. Efficient internalization in the cytosol of Hela cells enables MRI and optical cell imaging with no observable cytotoxic effects. 